Portland State University

PDXScholar

Spring 5-27-2016

\title{
Origin and Use of Pedagogical Content Knowledge: A Case Study of Three Math Teachers and Their Students
}

Christopher Neal Wood

Portland State University

Follow this and additional works at: https://pdxscholar.library.pdx.edu/open_access_etds

Part of the Science and Mathematics Education Commons Let us know how access to this document benefits you.

Recommended Citation

Wood, Christopher Neal, "Origin and Use of Pedagogical Content Knowledge: A Case Study of Three Math Teachers and Their Students" (2016). Dissertations and Theses. Paper 2957.

https://doi.org/10.15760/etd.2953

This Thesis is brought to you for free and open access. It has been accepted for inclusion in Dissertations and Theses by an authorized administrator of PDXScholar. Please contact us if we can make this document more accessible: pdxscholar@pdx.edu. 
Origin and Use of Pedagogical Content Knowledge:

A Case Study of Three Math Teachers and Their Students

by

Christopher Neal Wood

A thesis submitted in partial fulfillment of the requirements for the degree of

\author{
Master of Science in Teaching \\ in \\ General Science
}

Thesis Committee:

William Becker, Chair

Cary Sneider

Jerian Abel

Portland State University

2016 
Abstract

Teachers must have specific knowledge of a subject and how to teach it to promote learning in their students (also known as pedagogical content knowledge). Research has shown that project-based curriculum can be an effective way for teachers to leverage this knowledge into deeper student understanding and application readiness, but observations about when and how this happens in the classroom have not been adequately documented. In this study we will explore teaching and learning in a middle-school boat-building curriculum focused on real-world application of math concepts. The boatbuilding program took place over one week, included seven students, and was taught by three teachers. The teaching phase of this study examined how the three boat-building teachers applied their pedagogical content knowledge (PCK) through a participant observation case study. The three teachers had diverse training and teaching backgrounds. At the completion of the course these teachers were interviewed on their prior teaching experiences and training to determine how they acquired their pedagogical content knowledge. The learning part of this study involved a pre- and post-test application task completed by the students. After all students completed the application task, each was interviewed to see what, if any, knowledge or approach these teachers used had an impact on the ability of the students to do the task. Analysis of the pre-post assessments showed that students were not able to make statistically significant gains over the one week of instruction. However, students did note many aspects of instruction that they thought helped them. Additionally, 
students showed gains in assessing importance of geometry in design, the vocabulary associated with scale, geometry, and woodworking, and creating context for prior instruction. For the teachers, higher scores on the PCK rubric did align with a greater amount of experience teaching. Also, the two more experienced teachers influenced each other and the third teacher regarding student learning and instructional approach. 


\section{Dedication}

To all those whose believe children deserve meaningful educational experiences. 


\section{Acknowledgments}

Special thanks goes first and foremost to the present and past faculty of the Center for Science Education at Portland State University, for their guidance and support through this process. This would not have been possible without Stephanie Wagner, Cary Sneider, Jerian Abel, Melissa Potter, and William Becker. I would also like to thank my partners at the Wind \& Oar Boat School, Peter Crim and Jann Lane, for making me feel at home in their organization, and with all of the opportunities they provided me to see how their program impacts kids in every project. Thanks goes out to the teachers at the Boat School, for both teaching me about boat building and allowing me access to their thoughts and experiences as educators.

Finally, I would also like to thank the support, advice, and commiseration of my cohort, Ashley Fanning, Chessa Eckles-Anderson, Trisha Schlobohm, Megan Poole, Jo Linden, and Scott Barrentine. 
Abstract

Page

Dedication

iii

Acknowlwedgements

iv

List of Tables

vii

List of Figures

ix

1. Introduction

1

2. Literature Review

12

3. Methods

30

$\begin{array}{ll}\text { 4. Results } & 45\end{array}$

5. Discussion 86

$\begin{array}{lr}\text { References } & 105\end{array}$

Appendices

A. Portland Metro Stem Partnership PCK Rubric 109

B. Discrete Teacher Actions Sorted by Category Type 111

C. Portland Metro Stem Partnership Application of 113 Conceptual Knowledge Rubric

D. Modified Application of Conceptual Knowledge Rubrics 114

E. Assessment Task Verbal Instructions 115

F. Descriptions of Instructional Time Experienced 116 by Students

G. Teacher 1 Observation Details 118

H. Teacher 1 Interview Details $\quad 121$ 
I. Teacher 2 Observation Details 124

J. Teacher 2 Interview Details 127

K, Teacher 3 Observation Details 130

L, Teacher 3 Interview Details 134

M. PH Stat Raw Data Analysis 136

$\begin{array}{ll}\text { N. Approved IRB Application } & 137\end{array}$ 
Table 4.1 Student Conceptual Knowledge Assessment Results:

Table 4.2 Student Feature Set Accuracy:

Table 4.3 Student Application of Conceptual Knowledge Assessment Results: 49

Table 4.4 Student Assessment Change:

Table 4.5 Student Interview General Responses:

Table 4.6 Student Connections Between Geometry and Design:

Table 4.7 Student Vocabulary Comparison:

Table 4.8 Student Vocabulary Change:

Table 4.9 Teacher 1 Participant Observations and Interview Responses: $\quad 61$

Table 4.10 Teacher 1 PCK Rubric Scores: 64

Table 4.11 Teacher 2 Participant Observations and Interview Responses: $\quad 64$

Table 4.12 Teacher 2 PCK Rubric Scores: $\quad 67$

Table 4.13 Teacher 3 Participant Observations and Interview Responses: $\quad 68$

Table 4.14 Teacher 3 PCK Rubric Scores: $\quad 70$

Table 4.15 Student Interview General Responses: 72

Table 4.16 Student Interview Mentions of Specific Teachers: 72

Table 4.17 Score Change Attributed to Teachers: 73

Table 4.18 Examples of Co-Teaching: 78

Table 4.19 Boat School Co-Teaching Examples: 79

Table 4.20 Encouraging Different Learning Styles and Following Student Enthusiasm Observations, Change Over Time: 
Table 4.21 Anticipating Steps or Trouble in a Task Observations, Change Over Time: 
List of Figures

Page

Figure 3.1 Research Treatment: 32

Figure 4.1 Example Student Drawing Response: $\quad 47$

Figure 4.2 Stem Top View: 56 


\section{Introduction}

Like many people interested in education, I have memories of teachers who were inspiring and excelled at helping their students take concepts from the classroom and create something unique with them. On the other hand, I have been in classes where I felt like I would never do well, and that the teacher did not understand my problems in learning the material. In the latter situation, it is easy to feel that you are not good at that subject, or not smart in general.

Those teachers that I remember enjoying and learning the most seemed to have a strong grasp of their subject. This didn't always mean that they knew the answer to every question immediately, or that they felt the need to lecture a set of facts at their students in every period. Instead these teachers understood why the facts mattered, and how they would apply to their students' lives.

The best teachers cared about their subject and believed the ideas they were teaching were important, which was the hook for me. In time, what made me respect them was their ability to recognize a lack of understanding in their student. These teachers knew how to address misconceptions with patience and care. Students were presented with multiple approaches, and always made to feel capable of learning.

At the other end of the spectrum, I remember struggling in classes taught by teachers who did not have a deep grasp of the subject matter. One perspective of a concept was presented, and then the class moved on with or without everyone in the class reaching some understanding. As a student, this came off as a lack of caring, and did not instill confidence or curiosity in me. 
I would dread going to these classes, and in some cases was discouraged from the subject altogether. Every year this seemed to be the case for a majority of students of the same teachers. These teachers appeared to be unprepared to address the issues reoccurring each year for their students. I believe any of these teachers would have made an effort to change their instruction, but they lacked knowledge or experience to do so.

Ball et al. (2005) identifies two dimensions of pedagogical content knowledge (PCK): A teacher's general comprehension of the subject and knowledge of how to develop specific understanding of the subject. More specifically this is everything a teacher does or knows to do to promote learning and understanding in his or her students.

All teachers use both dimensions of PCK in their professional practice (Loo, 2012), but PCK is more refined in some teachers than others, and this leads to different applications of teaching specific knowledge (Shulman, 1986).

Teachers face their first years in the classroom with a limited range of PCK (Wilson et al., 2002). Teachers can approach these early years using the general pedagogy learned through their experiences during teacher preparation, or strategies based on similar experiences from past careers.

After that, further development of any individual teacher's PCK can take a variety of trajectories. Undoubtedly, teachers with reduced access to support and development opportunities are at a disadvantage to those with more opportunities. Additionally, other claims on a teacher's time will further reduce their chance to develop this essential set of skills. 
On the other hand, students are almost continually presented with new ideas and perspectives in school. This is the case whether students seek out these experiences or not. Some classes will challenge students to memorize and repeat, without any emphasis on making sense of the place these ideas have in the real world. More student-centered learning environments will challenge these students to apply conceptual knowledge, not simply remember it.

Both understanding of content knowledge and ability to apply this knowledge to unique situations are related to student understanding (Krathwohl, 2002). The application of conceptual knowledge is simply the ability to use knowledge with strong understanding of relationship to other concepts to solve new problems (Lingard, Mills, \& Hays, 2006). It is an interconnected understanding of concepts, where the relationships are as important as the concepts themselves.

Generally, both of these aspects of PCK are related to student achievement (Steele, 2013). More specifically, a specialized set of knowledge for teaching a specific concept is essential to creating an environment where students can learn to understand and apply concepts (Ball et al., 2005).

While these teacher and student challenges may seem removed from one another, they are related in direct ways. Most students and teachers, when faced with a new task, first rely on old skills to meet the challenge. However, often building new skills is required to truly excel at a given task.

Students can attempt to make sense of new ideas by comparing to concepts that they have already contextualized, without outside guidance; but if 
teachers are deeply versed in a subject and have many approaches in teaching, the students would learn faster and retain information better.

On the other hand, teachers can gain experience throughout their career, largely by trial and error. If teacher preparation programs could better target what experiences help teachers succeed, then teachers should be able to develop their PCK more rapidly.

While it has been shown that the acquisition of PCK is linked to a total amount of teaching experiences (van Driel et al., 1996), there is also evidence to support the idea that to develop this knowledge, teachers can also contextualize other relevant experiences, both related to teaching (Nason et al., 2012) and not (Jagede \& Taplin, 2000). The depth and breadth of experiences that contribute to the PCK is thus much larger than initially thought.

Students learn in the classroom through many of the same ways that their teachers acquire their PCK, through exposure and exploration. There are many ways for a teacher to create situations in their classrooms for students to learn in a less intimidating and more realistic environment. For example:

- Ormell (2005) conducted studies with 10-11 year-old students, and found that although they understood many mathematical science concepts they were not able to apply their concepts to new settings unless they were primed to do so with similar problems. He proposed that teachers should create more authentic real world tasks so that students would be primed to apply their skills when they encountered similar situations. 
- Gallagher (2000) showed, through a summary of decades of research, that teaching with a focus on application of concepts benefits a student by also enabling him or her to recognize how an idea is related to their life. This approach also creates more opportunities to create understanding in a student's future, as Gallagher showed that understanding one set of concepts could be used to learn another in much the same way.

- Finally, Hilton et al. (2013), showed that developing the ability to apply concepts of geometry takes time and repetition. A teacher with strong PCK would be expected to know about such research findings, and would therefore be expected to provide many different tasks to enable their students to practice applying geometry and scaling concepts in different situations, including some that relate to their everyday experiences. Presenting learning through investigating and solving intricate questions or problems explored over an extended period of time is often given the moniker project-based learning (PBL). Teachers design authentic tasks to challenge their students to apply conceptual knowledge as they are contextualizing many related ideas in a way that makes sense to each individual. Research into PBL in Science, Technology, Engineering, and Math (STEM) subjects is extensive, and most indicates that when used well, it is a strategy that positively impacts student outcomes. These studies include:

- Han and Carpenter (2014) surveyed attitudes of nearly 800 students towards STEM PBL. They found that students have a positive attitude towards many aspects of STEM PBL, including hands-on technology, and 
the interdisciplinary, collaborative, and the self-regulated natures of the method.

- Kanter (2009) examined a project that required teachers to create a demand for the students to apply new knowledge. Using relational studies, Kanter found that greater student achievement was observed in a well-designed PBL setting than in traditional instruction.

- Kanter and Schreck (2006) also showed through examination of a biology PBL curriculum that students were successful in completing and succeeding in PBL science curriculum, when teachers were well prepared in the project before the start. This suggests a link between PCK and implementation of PBL.

The documented links between positive student attitudes, an increase in the student ability to apply conceptual knowledge, and a greater development of pedagogical content knowledge in teachers when STEM PBL is used in the classroom indicates that this is a method worth investigating.

Recently, I examined a STEM PBL program called the Wind \& Oar Boat School, in Portland, Oregon. The Boat School experience is a standard set of instruction in building wooden boats, and lessons in the application of math, science, and craft aptitude required in doing so.

During this project, I worked with a group of students participating in this math-focused PBL experience. One task the students regularly needed to complete was taking measurements from a plan drawn to scale, and creating full size pieces for the project from these measurements. Students often struggled 
with the fractions, proportions, and spatial reasoning involved. Several math and science teachers associated with the program acknowledged that this is one of several common stumbling blocks for many upper-elementary and middle school students.

Because I do want to teach in a classroom, I have the desire to anticipate what obstacles to learning my students might have, and to be able to use a variety of approaches in addressing these issues. No student should have to feel that a subject is impossible for him or her, or that they are not cut out for learning at all. I began to wonder what it was about this set of concepts that students found difficult, and what specific experiences or knowledge teachers could use to address these difficulties. More specifically, through conducting this research, I hoped to learn how teacher's PCK developed, how teachers with different PCK taught, and what aspects of PCK have a positive affect on student learning.

The Boat School was selected for participation in this research for its use of PBL with a focus on conceptual application in math and science classrooms. The Boat School uses a unique blend of content instruction followed by reinforcement through hands-on use. Students in the program often cite the Boat School as one of the first real world applications they have seen for these concepts, if not math in general. The Boat School provides a unique context for teachers to apply their PCK, promising a unique source of information about how teachers use opportunities like this. 
I examined teacher PCK and student ability to apply conceptual knowledge through the framework of this PBL program. This teaching method is used by the Wind \& Oar Boat School to help students gain understanding and interrelate concepts across topics.

Three of the teachers at the Boat School were of interest to my research because of their diverse set of teaching experiences. I also took into account their different backgrounds in woodworking and craft. These experiences also inform how the teachers interact with students in the program, as there is also an emphasis on tool use, craft skill, and attention to detail.

The first teacher has no formal training in education or experiences in a formal classroom. However, this teacher's experiences in informal education and PBL are extensive and varied. Her history with the Boat School is shorter than the second teacher, and has only taught two classes with the program previously. She has also completed a certificate program in woodworking, and runs a small business completing a variety of woodworking and design projects for clients.

The second teacher has been formally trained in math education, completing an advanced degree in the subject and going through formal training for teaching in a traditional classroom. Additionally, he has experience as a substitute in this same setting. This training was relatively recent for him, however, and his total amount of teaching experiences are lower than some of the other teachers at the Boat School. He has been woodworking as an 
enthusiast for many years, and has also served as a high school substitute in related classes.

The third teacher has no formal or informal experience teaching. She works with a partner organization to the Boat School, and expressed interest in exploring and trying teaching in this program. She has also completed a certificate program in a mixed-discipline trade program, and currently works as a member of a fabrication team for a local maker-space.

The first question this research explored was: In what ways does the experiences and training of Wind \& Oar Boat School teachers affect their pedagogical content knowledge in teaching math? I was not only interested in how these teachers have gained and used their PCK. I also explored how the use of this knowledge affected student achievement. The second question this research explored was: How did the experience of the Wind \& Oar Boat School teachers affect the ability of middle school students to do a scale drawing? The hypothesis looking at this relationship was that student ability will have increased after completing the Boat School program as taught by each of these teachers an equal amount.

The independent variable for this study was the Boat School program and the teachers' application of PCK. The dependent variable was the ability of students to apply conceptual knowledge gained through the Boat School experience, as measured by an application task before and after the program.

I used a set of common instruments from the Portland Metro STEM Partnership (PMSP), a regional enterprise of public and private groups with a 
shared goal of reforming STEM education, to collect data on student achievement gains at the Boat School. These were used to standardize the way researchers can examine and compare instructional strategies and programs. These instruments allow researchers to look at new or contrasting ideas and evaluate them side-by-side. A set of common measurements for examining educational programs is necessary for continued conversation and development of aspects of quality instruction in STEM education. These should be based on existing research in the field, and be used extensively for validation purposes (Saxton et al., 2014).

In order to characterize the independent variable-the learning experience that students encounter in the Boat School-I used participant observation to explore what these teachers did in the classroom to help students understand scale and geometry concepts. I also conducted interviews with the three teachers to further examine how and where they learned to do what they did in the classroom. These observations and interview responses were examined through the use of a Pedagogical Content Knowledge Rubric, developed by the PMSP and the conductor of this research. Observations and conclusions from the first question of this study were used to understand the setting of the Boat School more generally.

The achievements of the students were measured through an application of conceptual knowledge task presented before and after the Boat School program. Student performance was assessed using an Application of Conceptual Knowledge Rubric also developed by the PMSP and the conductor of 
this research. Students were also interviewed after the application assessment, to ascertain any specific lessons given or approaches taken by either of the two teachers that the students found relevant to the task.

I hoped that by examining the students and teachers of the Boat School, I first would be able to learn what specific aspects of a teacher's PCK are effective in helping students develop application ready understanding of scale and geometry concepts. After determining what aspects of PCK are effective, I would be able to discover where that teacher developed their knowledge. Finally, I hoped to observe how these teachers worked within the framework of a science PBL program.

Determining what kinds of experiences have led to effective PCK will improve how future teachers are recruited, as well as guide the development of more targeted professional development opportunities. These opportunities will help teachers develop these skills more quickly. Furthermore, after identifying what ways PBL provides opportunities for teachers to use their PCK, it will be possible to pinpoint more opportunities for this teaching strategy, and implement it more effectively where it is already used. 


\section{Literature Review}

In this section, I have outlined research related to the ability of students to perform complex tasks related to their conceptual understanding of proportional reasoning, since the scale drawing task in this study incorporates aspects of proportional reasoning. The reviewed research also presents findings from studies exploring teacher knowledge and the effects that different curriculum approaches have on student achievement. Finally, I have surveyed methods and motivations behind developing assessments for use in STEM education. Levels of Understanding and Applying Mathematical Knowledge

Ormell (2005) summarized findings of a study conducted in the 1980s with a colleague. The author was interested in measuring student math application readiness, which he defines as a positive inclination to use arithmetic skills in solving real life problems. In preliminary research, the author noted rituals used by students to avoid actually using arithmetic, but to be successful in the real world these rituals need to be contextualized in a way that makes sense of the arithmetic skills. The researchers compiled short, relatable narratives of fictional children that illustrate grammatical, behavioral, logical, and mathematical mistakes. Around 300 children of ages ten and eleven participated in the study, where volunteers first read these narratives to the students, and then the students were allowed to read them for themselves to search for these mistakes. The assessments contained twelve mistakes, three of which were mathematical. Ormell and his colleague observed that students found nearly all 
of the nonmathematical mistakes, but rarely found even one of the mathematical mistakes. If primed with the knowledge about the types of mistakes they found in previous narratives, students often found all arithmetic mistakes in the next narrative. The author concludes that students are often capable of mathematical tasks, but have not contextualized their skills in a way that allows them to readily draw upon them. He argues that teachers need to create more authentic real world applications for mathematics skills. He also concludes that the more teachers prime the application of math in the real world, the more students will see the inherent risk in overlooking mathematical errors and gain a real reason to apply their knowledge.

Hilton et al. (2013) sought to develop an assessment tool that teachers can use to measure proportional reasoning skills in students. Teachers can use this assessment to understand student difficulties and the misconceptions that lead to these difficulties. School districts can also use this assessment to design professional development for teachers to better support the teaching methods that foster the development of proportional reasoning skills. The authors thought it was important to be able to assess proportional reasoning, as many research projects have listed it as a capstone to elementary math education as well as a cornerstone to higher mathematics. Hilton et al. designed this assessment using two levels of understanding and corresponding questions types, and received input from multiple teachers before implementation. The researchers also used recommendations from a literature review on design of the assessment questions to increase the validity of the tool. These 
recommendations included using a two-tier design for assessment questions, and keeping the structure of the first tier consistent using a True-False format. The first type of question was simple true or false responses to statements, while the second examined the kind of reasoning students used to get their true or false responses. The researchers piloted the assessment using 150 students at two schools, and then implemented it in 28 schools over three years, reaching over 2000 students. The authors then compiled the responses, and incorrect responses receiving ten percent or greater of the response total were analyzed in more detail. Hilton et al. found that the acquisition of proportional reasoning skills is slow and needs reinforcement often and in varying applications. Additionally, different problem types elicit different reasoning and varying degrees and sources of difficulty. The authors did recognize improvements in many types of proportional reasoning as age and years of school increased, such as comparing relationships between given values. Despite this, some types of proportional reasoning tasks were difficult for all ages in the study, as well as for adults in some of the literature review. These include problems where the respondent must first determine if a situation is proportional or not, and those using interpretation of visual representations.

Krathwohl (2002) attempted to revise Bloom's taxonomy (an outline and hierarchy of conceptual understanding) in order to better represent concrete examples of what deeper student understanding looks like. The revised taxonomy follows the basic structure of the original, starting with lower-level knowledge like "remember," and building to higher-level knowledge like 
"evaluate" and "create." While the original taxonomy was relatively rigid in these progressions, the revision allows for a bit of overlap during instruction. The revision also addresses how teachers and other educators use common terminology like "understand." This entails a change in the original passive dimensions towards ones framed with verbs for doing, as well as adding a metacognitive aspect to the objectives of education. Krathwohl argues that the revised two-dimensional taxonomy refocuses the objectives of education on more meaningful understandings, while still emphasizing the importance of a strong basic understanding in the lower dimensions. The author also proposes several uses of the revised taxonomy for teachers, such as using this tool to clarify objectives and assessments for a particular unit, as well as examine the emphasis on the different dimensions. After the completion of this unit, the teacher can use the taxonomy to assess how to improve the preparation of the unit or the teaching methods or future lessons.

The Ormell (2005) study indicated that students are very capable of meaningful understanding and applying concepts to novel situations. To be able to understand concepts well enough to apply them to new problems, we know that both basic content and deeper understanding are needed. Hilton et al. (2013) showed that in the case of proportional reasoning, students need rigorous and frequent practice to develop meaning. Failure to reinforce these concepts had been identified in students in later grades, as well as some adults. Krathwohl (2002), developed useful classifications for measuring application of conceptual knowledge in students. He views the taxonomy not as a hierarchy, 
but as integral components for understanding in students. Strong grounding in basic knowledge allows students to develop their knowledge.

\section{Pedagogical Content Knowledge}

Ball et al. (2005) researched the specific impacts teacher content knowledge has on student outcomes. By doing this, the authors proposed to create a "practice based portrait" of mathematics understanding for teaching. They set out to identify both the common knowledge of math as well as the math knowledge specific to teaching in order to build measures of teachers' PCK. To do this, the researchers collaborated with mathematicians, math educators, professional developers, project staff, and math teachers to create a domain map of relevant content areas, which they used to write multiple-choice questions for teachers. These assessment questions were related to situations teachers experience every day, and were written to have philosophically neutral correct answers that can be used to assess both common math skill as well as skills directly related to teaching math. This assessment was used with 700 first and second grade teachers. The researchers then compared the teacher assessments with their students' gains on the standardized Terra Nova test, reaching over 3000 students of these teachers. Ball et al. found both common and teaching specific content knowledge greatly predicted student gains on the Terra Nova. This correlation existed when controlling for the socioeconomic status of students, student absences, teachers' credentials and experience, and average math lesson lengths. The researchers observed a small negative correlation when controlling for both socioeconomic status of students and teacher 
knowledge, but a large negative correlation when controlling for the race of students. These negative correlations meant it was more likely for teachers with greater understanding to be teaching non-minority students of a higher socioeconomic status. Additionally, when comparing teachers in the average range on the assessment with those in the top 25 percent, the gains on the test were about equal to the difference in achievement due to socioeconomic status. Finally, the researchers noted that common and specific content knowledge could occur independently, with some teachers having a very deep common content knowledge, but very shallow teaching specific content knowledge. Ball et al. note that their definition of teaching is everything teachers do to support student understanding. Because they are capable of influencing student outcomes through teaching specific knowledge, teachers need a fluency in math language, explanation, and using symbols with care.

van Driel et al. (1996) wanted to explore the origins of pedagogical content knowledge of teachers. To observe this in real time, they designed an experimental lesson to identify aspects of pedagogical content knowledge that teachers can use to improve student acquisition of knowledge. This lesson targeted high school chemistry students and centered on chemical equilibrium. A corresponding workshop for the teachers was designed. The researchers then conducted the workshop with twelve voluntary high school chemistry teachers who had at least five years teaching experience. The authors tape-recorded the workshop and classroom implementation of the lessons for analysis. The teachers also responded to questionnaires, and the student work emerging from 
the lesson was analyzed. During the workshop, the teachers were exposed to weaknesses in their knowledge of the subject, and how these weaknesses manifested in their presentation to the students. Upon reflection after implementing the experimental lesson, teachers felt they had deepened their understanding of the problems students face with this particular concept, and with their own analogies for presenting the material. By the end of the reflection, the teachers had categorized two problematic frames of reference students often settle into when trying to understand dynamic chemical equilibrium, and described the methods successfully used to address each. This test revealed that teaching experience itself is the primary source of pedagogical content knowledge. The results also identified subject knowledge as a requirement for the accumulation of this pedagogical content knowledge. The researchers go so far as to argue from other literature that teachers will rely more on general pedagogy when teaching subjects they do not know well.

Steele (2013) explored one potential cause for the lag of student understanding in geometry and measurement-limited teacher knowledge. He used the paradigm of common content knowledge (the type teachers hope to instill in their students) and specialized content knowledge (their understanding of the content in the context of pedagogy) as the loci for improved student achievement in these areas. The author cites that while previous research has demonstrated a link between improving teacher content knowledge and the quality of interactions with students, more nuanced assessments for teachers are necessary for further examining the relationship. Specifically, Steele argues 
that the most promising assessment tools focus too heavily on getting answers and not on the process, thus garnering no data on common content knowledge and specialized content knowledge of the teacher. The author proposed an assessment built around three criteria: a grounding in context of teaching, the aspects and relationships of common and specialized content knowledge, and the nuances beyond answers including misconceptions and vectors for change. The treatment consisted of a six-week course for public university student teachers related to math knowledge needed for teaching at the middle school level. Twenty-five student teachers were enrolled in the course and completed the subsequent written assessment. Additionally, twenty of the twenty-five teachers also completed a lesson plan through interviews with the researcher. The written assessments were scored using a rubric designed to capture data on both accuracy of response as well as features of rationale and types of representations. The author evaluated results of the interviews by coding mathematical goals identified by the participating educators in their lesson plans. The researcher found a correlation to performance on specialized content knowledge assessment tasks and the quality of student instruction as revealed by the lesson plans. Those teachers with specialized content knowledge were more likely to engage in higher-order strategies for instruction in the classroom, such as multiple representations. Also, an unexplored correlation between common content knowledge and specialized content knowledge in teachers was linked to better ability to plan lesson goals and anticipate roadblocks for students. 
These articles show that teachers directly affect their students' ability to apply conceptual knowledge, and that they do this by using a set of skills called pedagogical content knowledge (Ball et al., 2005). Teachers can have different levels of pedagogical content knowledge, and get this knowledge from a variety of personal and professional experiences (van Driel et al., 1997). Furthermore, the literature shows that both content knowledge and pedagogical content knowledge are important for promoting student achievement (Ball et al., 2005; Steele, 2013).

Project-based Learning and PCK

Kanter and Schreck (2006) conducted research to see if students in urban classrooms could make meaningful understanding in biology coursework through a project-based science curriculum. Urban high school science teachers, science education researchers, informal science educators, and content experts designed the Disease Detectives project using information from a literature review and professional experience. The biology-based project was eight-to-ten weeks long, and designed as an investigation of a disease in a fictional town. They anticipated potential issues with differing student readiness, and that students with less prior knowledge would need more support. This design group then outlined specific supports that teachers might need to provide for certain concept areas. Teachers in the urban district where the study was conducted underwent professional development and monthly focus groups to ensure they were ready to provide this support, before nearly 400 students completed the Disease Detectives project. The researchers coded video data for 
qualitative results and analyzed content pre and post-tests for quantitative results. In the qualitative analysis, Kanter and Schreck looked for instances where students interacted with the teacher or other students, and were able to successfully find patterns, apply a concept, or practice another higher level application of knowledge. The researchers found that students are capable of all higher-level applications of knowledge, and that ongoing support from teachers helps further their abilities. For students without background in a certain concept, teacher support becomes essential for students to be able to make meaning of the concept through inquiry in the project. In the quantitative analysis, Kanter and Schreck compared the pre- and post-tests, then organized the data by concept area and measured gains in students based on how prepared they were before the program began. The authors found very large gains over all concepts, and large gains in each concept individually. The authors observed greater improvements in high-level knowledge, like those that required applying conceptual understanding to novel situations, than low-level, like those that required fact recall. They also observed a statistically significant larger gain in students who were already more exposed to these concepts, although the less prepared students also made large gains. The researchers conclude that meaningful understanding can be nurtured through a project-based science curriculum.

Kanter (2009) was interested in how teachers can best design a projectbased science curriculum. He goes about outlining the process by creating a seven-lesson biology curriculum around cells and energy transfer, called I, Bio. 
The researcher starts by outlining some guiding principles for a meaningful understanding, and then listing anticipated challenges and design approaches meant to address these challenges. Kanter created the guiding principles from a thorough literature review of similar project designs. These are listed as creating a demand for content knowledge, construction of knowledge by firsthand experience, and an organization of content knowledge. Then, a group of science teachers, science education researchers, and content experts assessed potential challenges to curriculum design, and how to create a project for students based on design approaches targeted at the specific challenges. Once this panel had compiled their design approaches, a dozen teachers implemented I, Bio in $376^{\text {th }}, 7^{\text {th }}$, and $8^{\text {th }}$ grade classes containing over 650 students. In addition to the project itself, students completed a pre- and post-test on the content knowledge, while teachers completed three hours of professional development emphasizing the curriculum every week. The pre- and post-test were designed using Bloom's taxonomy (graded at three levels) for measuring meaningful understanding. By implementing I, Bio for many students and assessing the students' knowledge acquisition, Kanter planned to modify the design approaches needed, as well as be able to judge the success of the project. A small, but statistically significant, improvement was observed in students who had completed the I, Bio project compared with mean knowledge gains in students at their grade level. Although the author does outline some limitations, like increased amount of time spent on the project as well as lack of a control group, he does argue that through conscientious design of project-based 
curriculum teachers can help their students gain greater levels of meaningful understanding.

Han and Carpenter (2014) set out to create an instrument for measuring student attitudes towards STEM project-based learning in Korea. The researchers thought that this was important because of the rise of this relatively new learning opportunity, and the inconsistency with evaluating the effectiveness from a student perspective. The authors detailed five factors of STEM project based learning through a literature review: self-regulated learning, interdisciplinary content, technology, collaboration, and hands-on activities. Additionally, the researchers identified three common questions: Are the identified factors that compose STEM project-based learning components corroborated by measurement of the student attitude survey? Are the selected items of the survey reasonable indicators of the construct of student attitude toward STEM project-based learning? What is the student attitude toward STEM project-based learning in Korean schools? From these categories and questions, the authors borrowed or adapted 51 items for a survey for students, utilizing a Likert scale. Han and Carpenter randomly selected 5 urban schools in Korea, and administered their survey to 785 middle school students. Before compiling the results, the authors hypothesized that student attitudes would depend heavily on individual learning style, although familiarity with any of the five factors would provide greater positive feelings. Statistical analysis of the responses validated all five factors, although some more strongly than others. Technology, collaboration, and hands-on activities all returned more positive 
results than interdisciplinary content. This seems to support the idea that familiar approaches to students (as in technology) would result in stronger positive feelings than those that might be unfamiliar (interdisciplinary content).

Kanter and Schreck (2006) showed that project-based learning is an effective way to nurture meaningful understanding in students. Kanter (2009) demonstrated that teachers could use this approach when designing a curriculum to explore specific subjects, although evaluating whether the magnitude of student improvement compared to the time invested is justified needs to be weighed in specific circumstances. Han and Carpenter (2014) showed that student attitudes are positive towards many aspects of projectbased learning, but some are better liked than others. Teachers should be mindful of their students' individual preferences and personalities when using project-based learning.

\section{Measuring STEM Instruction and Learning}

Stearns et al. (2012) set out to create a tool for measuring STEM projectbased learning classroom implementation. Their goal was not to create a tool for evaluating teachers, but to assess ideal implementation and opportunities for further professional development and support. The authors based their observational rubric on a literature review, which identified six objectives: project-based learning structure, project-based learning facilitation, student participation, resources, assessments, and classroom learning environment. Within these six objectives, 22 items were either created by the authors or adapted from other resources for inclusion in the rubric, with a section for 
supporting comments at each item. Observers underwent extensive training before testing this instrument, and must have passed within $95 \%$ agreement of the rubric developers before being allowed to participate. Once the observers were trained, the rubric was tested in secondary classrooms in the United States over three years. Initial scores were low, with teachers scoring in the range of one to two on a five point Likert scale. These initial scores were used to target professional development and professional learning community activities towards project-based learning implementation. These professional development and professional learning community activities were built around shared and supportive leadership, collective learning, shared personal practice, and a climate of shared beliefs and values. Over the course of the study, implementation improved for all teachers in all categories, reaching scores above three in all six objectives by the end of the study. The researchers showed that classroom observations could be used to guide professional development to improve teaching implementation of STEM project-based learning.

Stern and Ahlgren (2002) conducted a review of curriculum from several popular resources to examine how well these materials address the standards they were aligned to. Specifically, the authors looked at the assessment materials included with these curricula in order to see if they assessed what was really targeted by the standards, how much they actually reveal about student understanding of this concept, and usefulness in modifying instruction based on the results. The researchers stated that these assessments have an influence on every aspect of a student's education; if there is a lack of focused, quality 
assessments in standard materials then individual learning will suffer. Stern and Ahlgren started by collecting nine newly developed and widely used long-term (at least three-year progressions) middle-school science curricula. The researchers used an evaluation protocol validated in two previous studies with an agreement rate of $87 \%$. They compiled a team of analysts with background in either teaching science in middle school and high school classrooms or at the university level. This team was all trained in the same evaluation protocol, and this training was refined by discussions of initial assessments by presenting evidence from the texts for any given rating. Once the training was complete, two teams of two members each independently analyzed each set of materials. The evaluation and research teams found that most materials covered a similar range of topics, with a little bit more quality in physical sciences than life or earth sciences. All but two curricula scored "Poor" on testing of what a student actually knows about core ideas and usefulness in modification of instruction in physics and of those two, only one scored "Very Good." "Poor" scores could indicate having only a few high-quality assessments, or a large quantity of lowquality ones. In life and earth sciences no materials scored "Very Good" on either criteria. The authors provide examples of the types of assessments that test student application of concepts, which include deciding if an explanation of a phenomenon is true, predicting a new phenomenon, and deriving generalizations based on related instances. They also provide examples of assessments in the materials evaluated in this study that do not test application of concepts, nor provide guidance for teachers in modifying instruction based on 
results. These assessments may include answers determined by general knowledge rather than specific concept knowledge, answers that can be derived from "test-wiseness," or those lacking any indication to teachers what an application of the concept would look like.

Saxton et al. (2014) outlined the initial creation of a system of common ways of measuring and evaluating science teaching strategies. The authors felt this was an important task, because a common set of measurements will allow better research on and promotion of effective teaching methods for improving student outcomes. The Portland Metro STEM Partnership formed a committee composed of members of the partnership's various stakeholder organizations. First the partnership committee devised the three-vertex/three-layer Theory of Change, which encompasses affective, conceptual, and practice outcomes at the student, teacher, and professional development levels. This committee designed a three-step process to outline the measurement system. By looking at constructs and prioritizing them, evaluating what tools are available now, and making measurement tool selections, they have laid the groundwork for a common measurement in the partnership. The authors attempted to provide a method of measurement that will encompass interconnections in STEM education. The authors contended that now student assessments focus on virtually no aspects that tend to lead to a successful college or workplace experience. By layering student, teacher, and professional development outcomes, and compiling a set of tools to measure these outcomes, we can 
individually assess any aspect of these outcomes, or the interrelatedness between outcomes in any given program.

These articles have shown that assessing implementation of projectbased classroom instruction can lead to targeted professional development opportunities to improve teacher pedagogical content knowledge. Research has been done into teacher support of students in learning proportion and other math content, and some tools are especially useful when looking at applying conceptual knowledge. These tools and comparisons can be useful to a variety of stakeholders in education. Finally common measurement tools have been effective in assessing a project individually or in relation to similar curricula.

\section{Review Summary}

These studies have shown that students are very capable of complex understanding in science and math; however, they are not likely to be able to apply their understanding unless they have practice in doing so. Furthermore, project-based science and math were effective tools in promoting students' abilities to apply their conceptual knowledge in novel situations. These studies also showed that this ability is what makes a student college or career ready within the realm of STEM. There were a variety of ideas already about how to measure the application of conceptual knowledge in students, as well as what deep understanding means. By using these classroom observation and assessment instruments, my hope was that I could accurately quantify the effects that the Wind \& Oar Boat School had on students' deeper understanding and application of conceptual knowledge. 
These studies also demonstrated that teachers need to use a specific set of skills and knowledge to promote this ability in students, and that simply using a project-based curriculum is not enough. The knowledge required was not only about the content of the subject they teach; teachers needed a specialized pedagogical content knowledge, specific to how students learn a subject or concept, as well as a strong knowledge of the concept itself. Teachers gained these skills from many different personal and professional sources, and will have a varied toolbox when compared to other teachers with more limited experiences.

These two areas of the literature were key to the motivation behind my research. Through my research, I sought to determine what pedagogical content knowledge the Boat School teachers' had, and how their PCK directly influenced student outcomes, as measured by their abilities to apply conceptual knowledge of mathematics through the process of boat building. Specifically, I looked at how the pedagogical content knowledge of the Wind \& Oar Boat School teachers was developed, and how this affected middle school students' ability to apply the concepts necessary to do a scale drawing. This is an important avenue for research because it supports future assessment development as well as potential professional development for teachers within the realm of pedagogical content knowledge. In designing my assessments for the Boat School I used these recommendations to create something that can be used in and compared with research at other project-based STEM groups. 


\section{Methods}

\section{Overview}

The setting for this study was The Wind \& Oar Boat School, which uses a framework of a hands-on building experience to positively impact middle and high school students' math ability. Students participated in a one-week program consisting of thirty-five hours of instruction. They learned about the mathematics and craft skills that go into building a wooden boat. In addition to emphasizing craft skills, the Boat School has a focus on improving academic identity, motivational resilience, and application of knowledge (as defined by Lingard, Mills, and Hays, 2006).

This research consisted of two parts. The first was a deductive mixedmethods quasi-experimental study with cross-sectional measurements of a project-based curriculum's impact on student application of conceptual knowledge (ACK). The second was an inductive participant observation case study designed to explore the effects of a teacher's personal history on their knowledge of teaching. A teacher's knowledge of a subject, and how to teach it, is encompassed in their pedagogical content knowledge (PCK).

\section{Part 1: Student Learning}

The deductive mixed-methods quasi-experimental study with crosssectional measurements of a project-based curriculum's impact on student application of conceptual knowledge (ACK) was designed around students answering the following question: How does the experience of the Wind \& Oar Boat School affect the ability of middle school students to do a scale drawing? 
My hypothesis was based on the research of Kanter and Schreck (2006), who studied project-based science curriculum in an urban environment. The expectation going into this study was that students would increase their conceptual understanding of ideas related to scale, proportion, geometry, and fractions. Additionally, they will be able to take this new understanding and apply it in situations they have not seen before. I tested this theory as described above, but was open to other possibilities to explain the effects observed.

The independent variable was the Wind \& Oar Boat School experience. This experience was examined by the opportunities presented to students to use conceptual knowledge in a physical setting. This was similar to the research of Ormell (2005), who studied the readiness of students to apply their mathematical understanding in the real world. Additionally, the observations and conclusions from the first question of this study were used to inform the observations made about the Boat School more generally.

The dependent variable of this study was the students' ability to apply conceptual knowledge to novel problems. This was tested through a comparison of pre-and post-tests, which was scored using the Application of Conceptual Knowledge Rubric developed by the Portland Metro STEM Partnership. All participating students were also interviewed after the post assessment. These interviews focused on any potential connections the students made between specific instruction during the Boat School program and their ability to complete the conceptual knowledge post-test. Questions were also included about specific instruction from each of the three spot-lighted teachers. Through these 
interviews I hoped to make explicit connections between the program experience and any measured change in student achievement.

An outline of the treatment and measurement schedule for the second part of the study is included in Figure 3.1 below:

Figure 3.1 Research Treatment

$\begin{array}{lllllllllll}\mathrm{N} & \mathrm{O}_{1} \mathrm{X} & \mathrm{X} & \mathrm{X} & \mathrm{X} & \mathrm{X} & \mathrm{X} & \mathrm{X} & \mathrm{X} & \mathrm{X} & \mathrm{X} \mathrm{O}_{1} \mathrm{O}_{2}\end{array}$

$\mathrm{N}=$ Nonrandom group

$\mathrm{O}_{1}=$ Scale drawing pre-post test

$\mathrm{O}_{2}=$ Student interviews

$\mathrm{X}=$ Treatment

Part 2: Instructors' PCK

The second research question this project explored was: in what ways do the experiences and training of Wind \& Oar Boat School teachers affect their pedagogical content knowledge (PCK) in teaching math?

Ball et. al (2005) defined PCK as "anything a teacher does to support student understanding." A background of many relevant experiences has been shown to create a wide base of PCK for teachers to draw from in their professional roles. A teacher with strong PCK can address their students' misconceptions and anticipate their needs. Studies that examine experiences that have helped teachers develop strong PCK may have far-reaching impacts for professional development and teacher training courses, or how researchers think about recruiting effective teachers.

My hypothesis was based on the research of van Driel et. al (1997), who explored the real-time impacts of professional development workshops on PCK. I expected that the total amount of experience teaching would have been the 
greatest indicator of well-developed PCK. I expected another strong indicator would be the teacher's overall grasp of subject knowledge.

Data on the PCK of these Boat School teachers was collected through notes taken during and after participant observation sessions, the protocol used outlined by de Walt \& de Walt (2002). These took place throughout the course of the program. The observations were coded and then evaluated against the Pedagogical Content Knowledge Rubric, developed by the Portland Metro STEM Partnership. The teachers were also interviewed on their personal history in math education at the end of the study, in an attempt to probe origins and development of this specialized set of knowledge.

\section{Participants}

The participants in Part 1 of the study were three of the Wind \& Oar Boat School teachers. These teachers have different backgrounds in education, with one having completed a graduate degree in education as well as a teacher preparation course focusing on math, the second has extensive experience in informal education but no formal training, and the third has little experience with teaching at all. One is male, while two are female, all between 25 and 35 years of age. They have all been with the Boat School for less than one year. These three individuals were selected for their diversity of experience, as well as their preexisting employment with the program. Because of the intertwined nature of the two questions included in this research design, data collected from each part of the study may be used to inform observations made in this case study. 
A group of participants for the second question of this study was selected through a partnership with Girls Inc, a nonprofit organization that focuses on helping girls build confidence through life-changing experiences related to the unique challenges girls face. This study was conducted with students from this group ranging from the $5^{\text {th }}$ through the $9^{\text {th }}$ grades. These students attended schools in the Lake Oswego, Portland Public, and Beaverton School districts. Class size was 12 students, with the families of 5 students choosing not to participate in the study. This limited data collection to 7 of these students $(\mathrm{N} \approx$ 7). This group was nonrandomized, as students will be staying with their class assigned by the organization. No control group was observed.

The socio-economic status of this student population were all middle to upper middle class. Five of students were Caucasian, while the remaining two students were of Asian-American ancestry. All students were on summer break, but during the school year are enrolled in public middle or high schools in suburban school districts outside of Portland, OR. The class selected to participate was chosen based on Girls Inc.'s involvement in bringing students to the Wind \& Oar Boat School to participate in the program.

\section{Treatment}

The first research question, concerning the origin and use of PCK by three teachers was based on the observations I collected during the participant observation phase. Therefore, no treatment was administered or measured.

Treatment for the second research question was the Wind \& Oar Boat School program. This program offers a project-based math curriculum 
structured around a boat building experience for middle and high school students. The class involved in this study met for five days over one week, for eight hours each day. These classes focused on developing the scale, proportion, geometry, fractions, and woodworking skills required for building a boat.

The founder of the Wind \& Oar Boat School was inspired while being trained in the Building to Teach (B2T) program at the Alexandria Seaport Foundation in Virginia. Taking some elements of this model, he adapted the curriculum for the Bevin's Skiff used by B2T, as well as introducing a more advanced program for another boat, the Sand Dollar.

The program usually takes place in middle and high school classrooms, over 30-40 total project hours. This time is often spread over 1 to 8 weeks. Two to four teachers conduct the classes, with no more than 35 students participating. In addition to emphasizing craft skills, the Boat School has a focus on improving academic identity, motivational resilience, and application of knowledge.

The program is structured in a way that presents useful applications for math concepts students will have come across in their studies. This is intentionally done for many students who have never been presented with a real-world application for their mathematics studies. The purpose of helping students learn how math concepts are used to create an object is for them to recognize that they have personal potential for doing math.

Instruments

The two research questions of this study used both quantitative and qualitative tools to measure academic gains and explore any discrete teacher 
influences on these gains. The qualitative and quantitative teacher data came from classroom observations; quantitative student data consisted of pre- and post-tests; both were scored using rubrics. Qualitative data for both students and teachers was also gathered using semi-structured interviews. Details concerning each of these instruments are included below.

Participant Observations of Teachers. The data to explore the first research question of this proposal was collected through participant observations. These took place during instruction throughout the program, with notes also being compiled after instruction concludes each day. Observations were focused on the subject knowledge and teaching specific knowledge of the participating teachers, related to the outlined math and craft aptitude.

Data from the participant observation notes were then scored and evaluated based on the Pedagogical Content Knowledge Rubric, in order to compare and contrast the PCK of the three teachers. The rubric is composed of two dimensions, Knowledge of Student Thinking and Understanding and Use of Effective Strategies. All observations were scored in both dimensions of this instrument. The PCK Rubric was developed by the Portland Metro STEM Partnership. I made some adjustments to this rubric for use in this study. The rubric takes cues from the Lee et. al (2007) study assessing secondary science teacher PCK, the Schneider and Plasman (2011) study outlining science teacher learning progressions, and the Park et. al (2001) study of reform classroom alignment with PCK. The adapted PCK Rubric is included in Appendix A of this paper. 
Semi-Structured Teacher Interviews. At the conclusion of the study, the teachers were also interviewed on their personal history in math education, in an attempt to probe the origins and development of their specialized set of knowledge, as well as their understanding of how to foster the development of student understanding in math topics. These interviews were semi-structured, with questions adapted from the study of van Driel et. al (1997) where the research team probed the origins of teacher PCK. Following is a list of the teacher interview questions:

- How did you start teaching?

- What do you look for when you think a student is struggling?

- What strategies do you use for a student who is struggling?

- How do you shape your instruction based on what prior knowledge students come to class with?

- What experiences have taught you how to be a teacher?

Student Performance Assessment. The student pre- and post-test was to compose a $1 / 2$ scale drawing of a three-dimensional parallelogram, similar to a part of the boat they saw in the program. The students were also asked to compare similarities and differences between the scale drawing they made and the real life object.

The pre- and post-tests both encompassed the same task, but there were two versions of the physical object students were using to do the task. For the pretest, half of the students were presented with first version, and the others with the second. Upon administering the post-test, students were given the other 
version of the object. Counter-balancing the assessments reduced the threat to validity due to a testing effect, and took into account the possibility that forms A and B may not be equal in difficulty.

These student assessments were scored using the Application of Conceptual Knowledge Rubric. The ACK rubric is composed of two dimensions, a Demonstration of Conceptual Understanding and an Application of Conceptual Knowledge. The pre- and post-tests were assessed using both dimensions. The drawing task was assessed using the first dimension, while the comparison they made was assessed using the second dimension.

The ACK rubric was developed by the Portland Metro STEM Partnership. I made some adjustments for use in this study. This rubric was designed using conclusions from the Lee, Liu, and Linn (2011) study of knowledge integration, the Stern and Ahlgren (2002) study evaluating student assessment tasks, and the Feltovich, Spiro, and Coulson (1993) study detailing teaching and learning of conceptual understanding.

Semi-Structured Student Interviews. Each of the participating students was interviewed following the pre- and post-tests. These interviews were semistructured, in that several prepared questions were used, but the lines of inquiry were not rigid. Interview questions focused on how each student completed the test, any influence on their method they can trace back to the Boat School method or a particular teacher, and views on why completing the drawing with a faithful attention to the details of the original would be important. The following is a list of the student interview questions: 
- What did you do to make the drawing half the size of the real stem?

- What tools did you use, and how did you use them?

- Who taught you how to do this?

- What is another way you could have accomplished this task?

- Why do you think the stem is shaped the way it is on a boat?

\section{Procedure}

This study took place over the course of one week of 8-hour days with the Wind \& Oar Boat School. All interviews were conducted on the final day of the program. All students in the program were not enrolled concurrently in another math class, as this program took place during the school district's summer break.

On the first day of the program, all students were given a pre-test to assess their conceptual knowledge on ideas related to doing scale drawings; this included a task focused on applying scale, proportion, geometry, and fractions. At the conclusion of the boat-building experience, students were given a posttest that presented the same application task as the pre-test, but with a slightly different version of the physical object they were required to draw.

During the course of the experience, observations were recorded of the teacher-student interactions, and how they modeled and supported the understanding of these related concepts. This was accomplished through participating in the day's instructions, and at the end of each day organizing notes by referencing the PCK rubric immediately.

All students participating in the study were interviewed about their experience. Student achievement gains on the post-test were grouped based on 
the amount of improvement on their Application of Conceptual Knowledge Rubric score, and the results of this assessment associated with the interview responses. These interviews were conducted at the conclusion of the Boat School program.

Finally, interviews with the Boat School teachers took place in the week following the Boat School completion. I also compiled and included any references to their teaching style or specific activities mentioned from the student interviews if applicable as prompts in these interviews. Measures Used for Analysis

Data from the participant observation of and interviews with teachers were organized into five categories: "Leadership and Collaboration with Colleagues", “Work with Students", "Planning and Analysis", “Content Knowledge", and "Philosophy Towards Teaching".

These categories were created iteratively, by highlighting relevant concepts I found in the teacher's actions and responses, grouping similar concepts together, and then recategorizing the responses using the consolidated groupings. All teacher responses went through three phases of this process, until the five used did not contain responses that overlapped.

"Leadership and Collaboration with Colleagues" focused on how the teachers interacted with their peers to promote learning in their students. "Work with Students" encompassed actions taken by a teacher while interacting with students. "Planning and Analysis" referred to actions taken by a teacher before or after class to prepare for upcoming classes, or to make the same lesson 
better for the next time. "Content Knowledge" covers all background knowledge about a specific topic or concept being taught. Finally, "Philosophy Towards Teaching" applies to observations and responses pertaining to how teachers should teach or background experiences that prepare one to teach. A full list of discrete actions used to categorize data is included in Appendix B.

In addition to categorizing the teacher observations and interviews along these lines, myself and one other graduate student at Portland State scored the data using the two domains of the PMSP Pedagogical Content Knowledge (PCK) Rubric. These domains are the knowledge of student thinking about specific STEM topics, and the understanding and use of effective strategies for specific STEM topics. This rubric and details on scoring these two domains can be found in Appendix A.

The categories used to group the teacher observations and responses connect directly to the domains used in the PCK Rubric. Most observations found in "Planning and Analysis" and "Content Knowledge" would fall into a teacher's performance on the first domain, while most observations found in the categories "Leadership and Collaboration with Colleagues", "Work with Students", and "Philosophy Towards Teaching" would fall into the second domain. Connections made between the discrete observations of this study's teachers and the PCK Rubric domains were used to give a rubric score.

All teacher data collected through observation, interviews, and rubric scoring was organized and presented using a series of tables and basic descriptive statistics. Sums of observation and interview data were organized in 
raw form in tables, and described in detail in the Results, Discussion, and Appendix. Scores of the raw data from the Pedagogical Content Knowledge Rubric were also collected in a table, and described in detail in the Results, Discussion, and Appendix.

I scored the raw responses from the student assessments using the rubric for the task, modified from the PMSP Application of Conceptual Knowledge Rubric, along with one other graduate student. Sample responses were scored first, to align how raters were using the rubrics, before scoring the student data. All scores for the student data fell within one point for the two scorers. The original PMSP Application of Conceptual Knowledge Rubric can be found in Appendix C, while the version with specific instructions for scoring the student tasks can be found in Appendix D.

I first collected all student data, and calculated the total change from the pre-test to the post-test. I then analyzed the student assessment scores using a non-parametric alternative to a two-sample t-test. This statistical measure was used because the sample size was too small to make assumptions about the distribution of the population, and I did not have sufficient knowledge about this population's distribution.

The measure used was the Wilcoxon Rank Sum Test, run through the PHStat macro for Microsoft Excel. This test assigns ranks to each observed value, and compares the sum of the ranks observed in each sample to a hypothetical minimum sum that would be considered statistically significant. The data set was analyzed for a level of significance of .05. 
Student interview data not directly used in the assessment task was categorized based on connections they made between the assessment and various experiences throughout their lives. Based on a student's approach to completing the assessment, their responses were separated into "Intuition", "Prior Knowledge”, “Conceptual Understanding Unrelated to Task”, or the "Experience with the Wind \& Oar Boat School".

Attempts to Mitigate Limitations: Two methods were employed over the course of this study to limit any effects that the limitations of the measures may have had on the results. The first was face validity of the assessment tasks and rubric measures, and the second was the use of multiple scorers on all student responses.

Face validity was used to check that the tasks and measures were targeting what I thought they were targeting. Three other graduate students and one instructor within the department evaluated drafts of the assessment tasks and rubrics, and gave advice on what did and did not align with what I wanted to measure. I modified those sections that did not align with the group's consensus accordingly, using their input. This check also served as a point to limit the magnitude of change imposed upon the rubric designed by the PMSP. All efforts were made to limit the amount of language added to the rubric, while still being clear about how to score student data, during the discussion regarding face validity of the assessments.

Face validity is considered a weak measure of validity, as ultimately there is a subjective aspect to any judgment within this framework (Trochim, 2006). I 
attempted to strengthen the case presented in this check by enlisting only the opinions of members of the education research community. By using only experts in the field of education, I hoped to receive more educated judgments about the strength of the tasks and measures (Trochim, 2006).

By having all student responses graded by multiple scorers, standards of inter-rater reliability could be used to ensure scores align with the rubric criteria (Trochim, 2006). Inter-rater reliability was established through a calibration phase using data not included in this research study. The two scorers rated and discussed this sample data to ensure they were regularly scoring within one point on the rubric of one another. They were then given the research data to score, again coming to data that was within one point on the rubric for each student.

Inter-rater reliability allows us to assume that each piece of student data used in analysis is consistent, no matter when their tasks were scored (Trochim, 2006). As long as each scorer scored the same or within a certain range (in this case one point on the rubric) the score was recorded for analysis. 


\section{Results}

In several ways, I observed the students participating in the Wind \& Oar Boat School classes involved in learning concepts that were tested in the preand post-test assessments for this research study.

To fully understand what the students and teachers did and experienced this week, some time must be spent talking about observational data. The scores from all assessments will be supplemented with relevant observations collected during the week, so that the reader can fully appreciate what the teachers were doing and how that may have affected student performance on the assessments. Additionally, this study will attempt to connect what the teachers were doing, with where they themselves learned to teach.

This observational data is worth discussing not only as a way to inform quantitative data collected, but also for its relation to possible teacher professional development, as well as for future research studies to explore this or similar educational organizations.

\section{Findings of Students' Learning Gains}

General Student Assessment Data: In the Conceptual Knowledge domain task, one of the seven students improved, leading to an average change of .14 points on the scoring rubric. Student pre- and post-test Conceptual Knowledge rubric scores are organized in Table 4.1 below: 
Table 4.1 Student Conceptual Knowledge Assessment Results:

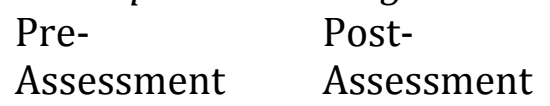

$\begin{array}{lll}\text { Student } 1 & 2 & 2 \\ \text { Student 2 } & 2 & 2 \\ \text { Student 3 } & 2 & 2 \\ \text { Student 4 } & 2 & 2 \\ \text { Student 5 } & 2 & 3 \\ \text { Student 6 } & 2 & 2 \\ \text { Student 7 } & 2 & 2\end{array}$

Rubric Scale: $0=$ little to no evidence to $4=$ strong evidence

Rubric used in this study available for review in Appendix $D$

The Conceptual Knowledge task consisted of students drawing a halfscale version of a pre-manufactured part of the boat (a stem). This drawing was to be done in a way that someone could use it in future to construct the stem to the same dimensions. The stem is a parallelogram, whose length was three times the width. The prompt with context and exact instructions given to students for the Conceptual Knowledge task can be found in Appendix E.

Students who scored a two in this task gave a response that is applicable to the question, but was inaccurate in either the angle of any corner or in the length of any side. Students who scored a three in this task gave a response that is not only applicable to the question, but was accurate in all angles and lengths. To score a four in this task, a student would have had to give a response that was applicable to the question, accurate in all angles and sides, and included information that would be helpful to constructing the stem in the future, but was not required in the prompt.

A response on this task was judged to be accurate if there were less than ten degrees of deviation for each angle, and less than $1 / 2$ inch deviation for each 
length. If any of the four angles or sides were outside of these parameters, the entire drawing was marked as incorrect.

When analyzing the student drawings, I took note of what feature sets (angles or side lengths) each student missed that caused their response to be marked as incorrect. Data is presented in Table 4.2 below, split into columns for pre- and post-test within each feature set.

Table 4.2 Student Feature Set Accuracy:

All Angles Correct All Side Lengths Feature Sets

$\begin{array}{lllll} & & \text { Correct } & \text { Correct } \\ \text { Student } 1 \text { Pre: } X & \text { Post: } & \text { Pre: Post: } X & \text { Pre: } 1 & \text { Post: } 1\end{array}$

Student 2 Pre: Post: $X \quad$ Pre: Post: Pre: 0 Post: 1

Student 3 Pre: Post: Pre: Post: $X$ Pre: 0 Post: 1

Student 4 Pre: Post: Pre: Post: Pre: 0 Post: 0

Student 5 Pre: Post: $X \quad$ Pre: Post: $X \quad$ Pre: 0 Post: 2

Student 6 Pre: Post: Pre: Post: Pre: 0 Post: 0

Student 7 Pre: Post: Pre: Post: Pre: 0 Post: 0

Total Pre: 1 Post: $2 \quad$ Pre: 0 Post: $3 \quad$ Pre: 1 Post: 5

More specifically, the errors made by students often went back to one of a few common misconceptions. Student drawings in general should have been a parallelogram, with one set of parallel sides longer than the other set. Figure 4.1 below shows an example of the general shape student drawings would resemble if done correctly, without figures that were included on actual assessments.

Figure 4.1 Example Student Drawing Response:

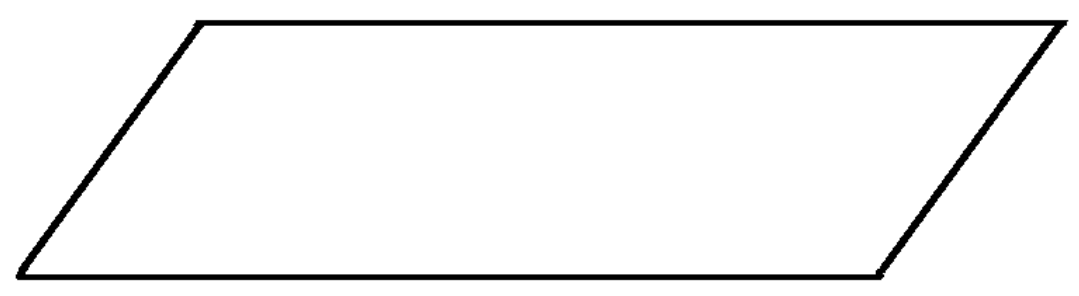


On drawings that students did not accurately represent the side lengths, 42.9 percent did not use the scale factor on the shorter pair of sides, while only 14.3 percent scaled the longer side incorrectly.

On drawings that students did not accurately represent the angles of the parallelogram, 28.6 percent simply used right angles rather than pairs of acute and obtuse angles, while another 28.6 percent correctly showed one pair of acute and one pair of obtuse angles but were not accurately able to represent these angles. Finally, 14.3 percent inverted one pair of angles, creating a trapezoidal shape rather than a parallelogram.

Students were most likely to get the side lengths correct in these assessments, although this is by a slim margin. Looking at specific incorrect student responses most of the side lengths were very close to the tolerances set for assessment, while with the angles students were more likely to be very far from correct.

In the Application of Conceptual Knowledge domain task, four of the seven students showed improvement, leading to an average change of .71 points on the scoring rubric. Student pre- and post-test Application of Conceptual Knowledge rubric scores are organized in Table 4.3 below: 
Table 4.3 Student Application of Conceptual Knowledge Assessment Results:

Pre- Post-

Assessment Assessment

Student 1

Student 2

Student 3

Student 4

44

Student 5

Student 6

Student 7

$2 \quad 4$

$3 \quad 3$

$3 \quad 3$

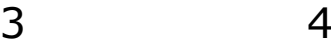

12

12

Rubric Scale: $0=$ little to no evidence to $4=$ strong evidence

Rubric used in this study available for review in AppendixE

The Application of Conceptual Knowledge task consisted of students talking about how the scale drawing they did compared to the real stem. They were specifically asked what was similar and different between their drawing and the real part. Additionally, they were asked how useful they thought their drawing would be to someone trying to make a stem in the future. This task relates to Dimension 2, Task 3, in the PMSP Application of Conceptual Knowledge Task Categories, "Consider the appropriateness of a representation for an idea or compare a representation with the real thing" (PMSP, 2014).

Students who scored a one in this task either did not give a response or the response did not address the question. Students who scored a two in this task gave a response that is applicable to the question but was inaccurate, or a response that only addressed similarities, or differences, or applicability to future boat builders, but not all three. Students who scored a three in this task gave a response that is applicable to the question, as well as shows a basic understanding of both the similarities and differences between their drawing and the real stem, as well as the applicability of the drawing to future builders. 
Students who scored a four in this task gave a response that is applicable to the question, as well as shows a more advanced understanding of both the similarities and differences between their drawing and the real stem, as well as the applicability of the drawing to future builders.

The rubric outlined more thoroughly the differences between an answer that scored a three and one that scored a four. General understanding was considered basic appearance of the stem, that the shape of the object remained the same, for example. Advanced understanding was tied to mathematical principles, that the proportions of the two pairs of parallel sides remained the same, as an example. A copy of the rubric used by scorers when assessing the student task, with specific criteria to be used for scoring, is included in Appendix D.

Overall, four of the seven students showed improvement in at least one domain of the assessment. Four of the improved scores were one point higher on the rubric from pre- to post-test, with one of the improved scores showing a two-point gain. Table 4.4 details the change for each student from the pre- to the post-test below: 
Table 4.4 Student Assessment Change:

$\begin{array}{lll} & \text { Conceptual Knowledge } & \text { Application of Conceptual } \\ & \text { Task Change } & \text { Knowledge Change } \\ \text { Student 1 } & 0 & 0 \\ \text { Student 2 } & 0 & +2 \\ \text { Student 3 } & 0 & 0 \\ \text { Student 4 } & 0 & 0 \\ \text { Student 5 } & +1 & +1 \\ \text { Student 6 } & 0 & +1 \\ \text { Student 7 } & 0 & +1 \\ \text { Rubric Scale: } 0=\text { little to no evidence to 4=strong evidence } & \\ \text { Rubric used for this study available for review in Appendix D } & \end{array}$

Student Classroom Experiences: Students engaged in instructional time that can be categorized into three types of classes. Those focused on skills with tools and building methods, those focused on math concepts related to boat building, and motivation and encouragement in alignment with the Girls Inc. mission ("to inspire girls to be strong, smart, and bold" (Girls Inc., 2016)

At the beginning of the week the teachers spent most of the instructional time helping students develop skill with tools and building methods. The teachers noted on several occasions that this is the usual formula, to ensure that all students will be able to work on the boat throughout the week, regardless of their history with tools.

On the first day, students spent time learning about the measuring tape, $\mathrm{f}$ style clamp, power drill, hand saw, and hand plane. Supplemental refreshers or introduction to more specialized tools was conducted as needed throughout the week.

These classes helped the students work on the boat, the focus of the relevance for all of the math concepts they were also learning. Self-efficacy in 
belonging in this type of class and environment was built up through structured challenges and support to succeed.

Instructional time for learning math concepts was more evenly spread throughout the week. Teacher 2 noted that he is constantly assessing each student's math knowledge while they use tools like the tape measure, so supplemental instruction can be supplied in addition to those lessons preplanned for all students.

Specific math lessons included a volume and buoyancy experiment with model boats, scale and proportion practice with creating parts for the boat from the plans, and discussions of surface area both in the shape of the boat and in applications like glues.

These classes helped the students understand how to built the parts of the boat with the tools they now knew how to use. Scale, proportion, precision, accuracy, and other concepts about relationships between things were all integral to succeeding in these tasks.

The motivational and encouragement time was most prevalent in the middle of the week. These were somewhat new experiences for both the teachers of this class in particular, and the Boat School in general. The Boat School teachers, at the request of Girls Inc. when creating this partnership, designed these experiences.

The largest experience that fit into this category was a drawing and teambuilding activity, group video screening, and discussion with the female teachers of the Boat School, about Laura Dekker. Dekker, at age 14 was the 
youngest person to ever circumnavigate the world by sailboat alone. The next largest experience was a set of three talks with female builders and business owners that spend time at the maker's space where the Boat School instruction took place.

These classes helped the students again feel as if they belonged in this class, and were capable of everything they were asked to do. Teacher 1 and Teacher 3 were surprised that none of these students ever expressed an opinion that girls could not or should not be builders. They both commented in some degree that there are very real obstacles to being a female maker or builder, and they were happy to see that these girls thought they could do it.

More detailed descriptions of student experiences in each of these categories of instructional time with the Wind \& Oar Boat School can be found in Appendix F.

General Student Interview Responses: During the interviews, students were asked about their time with the Wind \& Oar Boat School, both related to the assessment task and the experience in general. Table 4.5 below includes student responses, and mentions of how they understood specific concepts they worked with throughout the week: 
Table 4.5 Student Interview General Responses:

$\begin{array}{lllll} & \text { "Intuition" } & \begin{array}{l}\text { "Prior } \\ \text { Knowledge" }\end{array} & \begin{array}{l}\text { "Conceptual } \\ \text { Understanding } \\ \text { Unrelated to } \\ \text { Assessment" }\end{array} & \begin{array}{l}\text { "Experience } \\ \text { with the Wind \& } \\ \text { Oar Boat School } \\ \text { Teachers" }\end{array} \\ \text { Student 1 } & 1 & 0 & 4 & 5 \\ \text { Student 2 } & 0 & 0 & 4 & 3 \\ \text { Student 3 } & 0 & 3 & 1 & 5 \\ \text { Student 4 } & 1 & 0 & 4 & 3 \\ \text { Student 5 } & 1 & 0 & 4 & 5 \\ \text { Student 6 } & 2 & 2 & 1 & 3 \\ \text { Student 7 } & 1 & 0 & 1 & 4 \\ \text { Total } & 6 & 5 & 19 & 28\end{array}$

One trend that showed up in the results from the interviews was the mention of connections students made between the Boat School program and what they were asked to do in their assessment. All seven students made some connection between the Boat School instruction and skills required for the assessment, for a total of 28 mentions in the student interviews.

Student 3 said, "Practicing the angles was important we practiced this week for this drawing. Practicing using inches for measuring all week was helpful for this drawing. We used the tape for finding screw spots for the rails on the boat, but I had used a measuring tape before." Student 7 used similar tools, but without the prior experience. She said, "I used the tape measure and ruler and the stem to do my drawing. I took the ruler, then measured and divided, took measuring tape and did the line in the middle then the one next to it. Doing this reminded me of working on the frames."

Student 3's responses lead to another interesting pattern that emerged from the data, the mention of prior experiences in math classes in school. Two 
students mentioned a connection they made to previous lessons, with a total of five mentions from the interviews.

Student 3 said, "I had done a drawing like this before, where I divided the measurements I took to draw. I have used rulers to make a drawing of a Rubik's cube bigger in math class before." Student 6 also connected the Boat School to her math class, saying "In math tutoring we did drawings of a triangle, and I knew the stem should change size but didn't measure it."

Other Student Learning: While students were not able to apply the concepts of scale and geometry to their drawings at the level I expected, students did show a change in how they were thinking about the relationship between the structure of the boat and the function of its parts. Table 4.6 below shows the prevalence of interview responses related to geometry in boat design:

Table 4.6 Student Connections Between Geometry and Design: Mentioned how the Mentioned how the geometry of stem related geometry of stem related to boat design in preinterview to boat design in postinterview

Student 1

Student 2

Student 3

Student 4

Student 5

Student 6

Student 7

$$
\begin{aligned}
& X \\
& X \\
& X \\
& X \\
& X \\
& X
\end{aligned}
$$

In the post-interview, six students mentioned an aspect of the shape, size, or the mitre angle of the stem for joining the sides, and how these geometrical qualities had a specific function in achieving the structure of the boat design. 
This is compared to no students mentioning this about the design of the stem in the pre-interview.

Some students related the angle at which the miter for the sides is cut to how much material would be left in the stem in their post-interview. Student 4 noted that if the angle was cut deeper, there would be less material left in the stem, and it might weaken this component, much like the centerframe that broke.

This feature of the stem was not something students were asked to include in their drawing. An alternate view of the stem (from the top) is included in Figure 4.2 below, to demonstrate what specifically this student was talking about.

Fig. 4.2 Stem Top View:

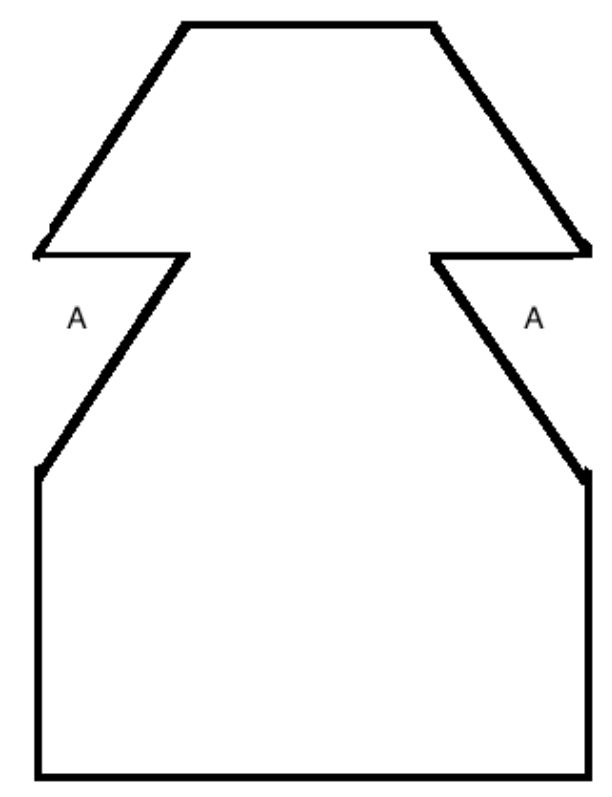

Sides secured with screws and glue at location " $A$ ".

Some students related the angle at which the miter for the sides is cut to how the sides attach, and what that angle means for the overall shape of the boat in their post-interview. Student 1 said that the entire shape of the boat is 
determined by the angle the sides leave the stem. She also mentioned that she did not think in a two-dimensional drawing of only one side of the stem would it be clear to someone else using her plan what angle to make this groove. Student 3 also mentioned that the angle at which the sides attached to the stem defined the curve of the boat.

Some students related the overall size of the stem to the size of the boat in their post-interview. Student 7 said that she thought a bigger boat would need a taller and thicker stem. It would need to be taller, because a larger boat would likely need taller sides since it would sit lower in the water. It would need to be thicker because the sides would curve more and put more pressure on the stem where the sides join.

Overall, before the class started students were likely to talk about what the function of the stem was ("holding the sides together") but not about how the specific design of the stem was important to the shape and function of the boat they would be building. After the class, students could relate specific aspects of the stem's shape to a function, and think abstractly about what a change to the stem would mean for the rest of the boat.

Students also showed a change in how they talked about their understanding of scale and geometry, as well as their use of specific building terms to explain their experience. A comparison of pre-interview vocabulary, juxtaposed with more precise post-interview vocabulary is found in Table 4.7 below: 
Table 4.7 Student Vocabulary Comparison:

\begin{tabular}{|c|c|c|c|}
\hline General & Specific & General & Specific \\
\hline Scale/Geometry & Scale/Geometry & Woodworking & Woodworking \\
\hline Vocabulary & Vocabulary & $\begin{array}{l}\text { and Building } \\
\text { Vocabulary }\end{array}$ & $\begin{array}{l}\text { and Building } \\
\text { Vocabulary }\end{array}$ \\
\hline tilted & angle (right, acute) & (none) & bevel gauge \\
\hline ladowing & $\begin{array}{l}\text { dimension }(2 \\
\text { dimensional and } 3 \\
\text { dimensional }\end{array}$ & ruler & straight edge \\
\hline divot & bevel & & \\
\hline & $\begin{array}{l}\text { scale or } \\
\text { proportion }\end{array}$ & (no & easure \\
\hline (none) & compound angle & (none) & combo square \\
\hline
\end{tabular}

Overall, only one student consistently used the more specific vocabulary to explain her understanding of the assessment task in the pre-interview, while all seven used the more descriptive vocabulary in the post-interview. This change is documented in Table 4.8 below:

Table 4.8 Student Vocabulary Change:

Mentioned specific math Mentioned specific math or building vocabulary in or building vocabulary in pre-interview post-interview

$\begin{array}{lll}\text { Student } 1 & \mathrm{X} & \mathrm{X} \\ \text { Student } 2 & \mathrm{X} \\ \text { Student } 3 & & \mathrm{X} \\ \text { Student } 4 & & \mathrm{X} \\ \text { Student } 5 & & \mathrm{X} \\ \text { Student } 6 & & \mathrm{X} \\ \text { Student } 7 & & \mathrm{X}\end{array}$

Student 4 described her drawing in the pre-test as similar to the real stem "because it is shaded to look like there is a gap." She described her differences by saying "(it) does not look like the stem because it is not tilted." When finished with the post-test, she said her drawing looked similar because, "The groove is obviously 3-dimensional, so I think that people will be able to see that." She 
thought the differences were mainly related to the dimensions, saying "the right side is too big at the top. This makes the angle more acute than it should be."

Student 7 said after the pre-test that she wasn't even really sure how to do the drawing, so she just guessed. After the post-test she confidently declared, "I used the tape measure and ruler and the stem to do my drawing." She also went more in depth into her method, saying "I took the ruler, then measured and divided, took measuring tape and did the line in the middle then the one next to it. Then I used the bevel gauge to do the angles after I knew how big to make it."

Overall, students were able to both more accurately describe the function of the stem in the overall function of the boat. They were also more precise with the vocabulary they could use to explain their ideas in the post-test.

Student Data Summary: The students were not observed to improve in their ability to do a scale drawing after completing the Wind \& Oar Boat School program. Students were able to make connections between what the teachers did during the week, and lessons that they have had in the past in their traditional school setting. They were also able to make connections between the lessons of the Boat School during the week and the assessment task.

Other changes in student behavior and ability were observed that were not within the scope of the original research question. These changes were observed in both the participant observations among the students, as well as in their interview responses.

The first change observed was a shift to more specific geometry, scale, and woodworking vocabulary. The second change observed was a greater 
application to geometry and scale when describing real-world design. The third change was an apparent increase in understanding of concepts previously covered in their traditional classrooms.

\section{Teacher Observations and Interviews}

In many instances I observed the teachers involved in this study engaged in activities in the classroom that aligned with what they said was important to their role as a teacher during the interviews. How each expressed their values varied, even within one observed category. In a few instances I observed that what they spent time doing varied substantially from what they said was important. Additionally, I observed some interplay between teachers and adoption of new styles. All of the teacher's exhibited a unique "fingerprint" in their practice, which is individually identifiable and tied to their past experiences and training. This "fingerprint" includes all of the observed practices and self-reported thoughts or philosophies a teacher holds towards their profession. These "fingerprints" are described in the following case studies.

Teacher 1 Case Study: Teacher 1's "fingerprint" was characterized by the large amount of time spent during the class engaged in activities classified as "Working with Students," with the next most common category of activities being "Planning and Analysis." Her "fingerprint" was also characterized by the amount of time spent talking about activities categorized as "Planning and Analysis" in her interviews. The second most common category of activity she talked about during her interviews was tied between "Working with Students" 
and "Philosophy Towards Teaching". Table 4.9 contains a general outline of Teacher 1's observation and interview results:

Table 4.9 Teacher 1 Participant Observations and Interview Responses:

$\begin{array}{llllll} & \begin{array}{l}\text { "Leading and } \\ \text { Collaborating } \\ \text { with } \\ \text { Colleagues" }\end{array} & \begin{array}{l}\text { With } \\ \text { Students" }\end{array} & \begin{array}{l}\text { "Planning } \\ \text { and } \\ \text { Analysis" }\end{array} & \begin{array}{l}\text { "Content } \\ \text { Knowledge" }\end{array} & \begin{array}{l}\text { "Philosophy } \\ \text { Towards } \\ \text { Teaching" }\end{array} \\ \begin{array}{l}\text { Observations } \\ \text { (\% of total) } \\ \text { Responses }\end{array} & 0(4.8) & 20(47.6) & 10(23.8) & 4(9.5) & 6(14.3) \\ \text { (\%) } & 7(28.0) & 9(36.0) & 2(8.0) & 7(28.0)\end{array}$

(\% of total)

More specifically, Teacher 1 tended to use her time in class engaging in one of the two following specific activities:

- Checking in with students or other teachers about how a lesson went, and what would help as student learn it better in the future (categorized as "Working with Students" and "Planning and Analysis")

- Finding a balance between allowing each student to explore to determine a method that works best for them, and giving explicit instructions when students were overly frustrated or about to do something dangerous. (categorized as "Working with Students")

Detailed descriptions of observational instances that align with these actions, and how these teaching methods supported student learning can be found in Appendix G.

During her interview, Teacher 1 more specifically mentioned that the following activities are important to being a teacher:

- Taking time to debrief each day of instruction (categorized as "Planning and Analysis") 
- The ways she thinks a teacher can create positive interpersonal relationships with students (categorized as "Philosophy Towards Teaching")

Teacher 1's response frequencies varied from the observation data by greater than 10\% in the "Working with Students", "Planning and Analysis", and "Philosophy Towards Teaching” categories. Her response frequencies corresponded within $10 \%$ in the "Leading and Collaborating with Colleagues" and "Content Knowledge" categories.

Teacher 1 said she thought students benefitted from useful feedback from a teacher that they had a good relationship with, because they could trust that their teacher had their best interest at heart and it gave them something to focus on improving. This means that a teacher not only needs to know enough about a subject to critique student work, but also needs to first establish and then maintain a positive relationship with a student to make the feedback as effective as possible. Teacher 1 said her creative writing professor from college was one influence on her interest in teaching. He was a powerful giver of feedback and adept at arranging the room so that students would feel inclusive during class discussions.

To create a positive relationship with students, Teacher 1 talked about her experience as a tutor working for a private company in Seattle, WA. In particular, her coworkers in this job were memorable for the lessons they taught her about relating to students and treating pupils with respect. Teacher 1 said that her coworkers at this job made her think about how teaching is as much 
about how a teacher needs students to really open up to share their ideas as they are forming, without judgment. Again, this positive relationship was very important for Teacher 1 .

More detailed descriptions of experiences Teacher 1 talked about in her interview, and how she thought these supported her student's learning, can be found in Appendix $\mathrm{H}$.

When Teacher 1's observations and interviews were scored on the PCK Rubric, she received a two out of four in the first domain (Knowledge of Student Thinking about Specific STEM Topics). This was primarily due to her consideration of grade level and developmental appropriateness of approaches to specific STEM topics. Without a strong background in concept progression in classroom math standards, Teacher 1 relied heavily on the background of Teacher 2 to develop lessons each day.

Teacher 1 scored a three out of four in the second domain (Understanding and Use of the Effective Strategies for Specific STEM Topics) of the PCK rubric, primarily due to her ability to implement inquiry-based instruction; as well as her knowledge of representations of STEM concepts that are pedagogically sound, accurate and unlikely to develop misconceptions in her students. Her use of developmentally appropriate language for STEM topics did score higher on the PCK rubric. Teacher 1's rubric scores are included in Table 4.10 below: 
Table 4.10 Teacher 1 PCK Rubric Scores

Knowledge of Student Understanding and Use of

Thinking about Specific the Effective Strategies for STEM Topics

a.) 3

b.) 2

c.) 3

d.) 3

e.) 4

Overall $2 \quad 3$

Rubric Scale: $0=$ little to no evidence to $4=$ strong evidence

Rubric available for review in Appendix A

Teacher 2 Case Study: The instructional "fingerprint" for Teacher 2 was

also characterized by the large proportion of time he spent on activities

classified as "Working With Students," with the next most common activities

classified as "Leading and Collaborating with Colleagues." His "fingerprint" was

also characterized by the amount of time spent talking about "Philosophy

Towards Teaching" in his interviews. The next most common activity he talked

about was "Working with Students." Teacher 2's observation and interview

results are included in Table 4.11 below:

Table 4.11 Teacher 2 Participant Observations and Interview Responses:

"Leading and "Working "Planning "Content "Philosophy

Collaborating With and Knowledge" Towards

with Students" Analysis" Teaching"

Colleagues"

$\begin{array}{lllll}\text { Observations } & 10(25.0) & 12(30.0) & 4(10.0) & 8(20.0)\end{array} 6(15.0)$

(\% of total)

Responses $\quad 3(10.3) \quad 7(24.1) \quad 5(17.2) \quad 6(20.7) \quad 8(27.6)$

(\% of total)

More specifically, Teacher 2 spent his time in class engaged in the following activities: 
- Working with students giving explicit instructions or lessons, and stepping in to help on projects that students were struggling with (categorized as "Working with Students")

- Preparing the other two instructors for the upcoming lessons and activities, and following up on lists of materials that needed to be acquired and prepared for the next day based on the other teachers' recommendations (categorized as "Leading and Collaborating with Colleagues")

Detailed descriptions of observational instances that align with these actions, and how these supported student learning, can be found in Appendix I. During his interview, Teacher 2 more specifically mentioned that the following activities are important to being a teacher:

- Knowing or finding out where students are starting in their understanding of a concept when first coming to his class (categorized as "Philosophy Towards Teaching")

- Asking questions as a method of instruction (categorized as "Working with Students")

Teacher 2's response frequencies differed from observation data by greater than $10 \%$ in the "Leading and Collaborating with Colleagues" and "Philosophy Towards Teaching" categories. His response frequencies corresponded with the observation data within $10 \%$ in the "Working with Students," "Planning and Analysis," and "Content Knowledge" categories. 
Teacher 2 said he thought it was important to challenge their students to push the boundaries of their abilities. He said an important skill a teacher should have to challenge their students is being able to figure out what ideas a student has. A teacher has to know where a student is to be able to move them forward. Like Teacher 1, Teacher 2 also talked about a previous teacher having an influence on his desire to and style of teaching. In his case, this was his high school wood-working teacher, who inspired him constantly to never rest with his current proficiency. This teacher also inspired his interest in applied math and the challenges that come with visualizing intricate concepts.

He also talked about the cooperating teacher from his time student teaching, who, while not the most inspiring teacher, still helped him hone his classroom management skills. He credits his proactive style, something he notes is not much like his usual personality, to her guidance. He thinks that being active with classroom management sets up high expectations for students, which in turn creates a more academic and productive classroom. High expectations can in turn help students to succeed by clearly valuing giving your best effort at all times.

More detailed descriptions of experiences Teacher 2 talked about in his interview, and how he saw these as related to student learning, can be found in Appendix J.

When I scored both his observations and interview responses on the PCK Rubric, Teacher 2 received a three out of four in the first domain (Knowledge of Student Thinking about Specific STEM Topics). This was primarily due to his 
understanding of prior student knowledge and common misconceptions. Most of his interactions with students were developmentally appropriate.

He scored a three out of four in the second domain of the PCK rubric (Understanding and Use of the Effective Strategies for Specific STEM Topics) primarily due to his use of inquiry strategies in teaching and use of STEM specific language. His understanding of pedagogically sound representations for STEM topics based on a student's background did score higher on the PCK rubric, while his use of developmentally appropriate language was the weakest of these three criteria.

Teacher 1 often stepped in throughout the week to remind Teacher 2 of language that is specific to STEM topics as compared to what students were familiar with. Teacher 2's PCK rubric score are included in Table 4.12 below:

Table 4.12 Teacher 2 PCK Rubric Scores

Knowledge of Student Understanding and Use of Thinking about Specific the Effective Strategies for STEM Topics Specific STEM Topics

$\begin{array}{ll}\text { a.) } & 3 \\ \text { b.) } & 3\end{array}$

c.) 3

d.) 4

e.) 3

Overall 3

Rubric Scale: $0=$ little to no evidence to $4=$ strong evidence Rubric available for review in Appendix A

Teacher 3 Case Study: Teacher 3's "fingerprint" was characterized by the amount of time spent on her two most common activities, those classified as "Working with Students" and "Planning and Analysis." The next most common activities were classified as "Content Knowledge." Her "fingerprint" was also 
characterized by the amount time she talked about activities categorized as "Planning and Analysis" in her interviews. The next most common activities she talked about were categorized as "Content Knowledge." Table 4.13 below details Teacher 3's observations and responses:

Table 4.13 Teacher 3 Participant Observations and Interview Responses:

\begin{tabular}{|c|c|c|c|c|c|}
\hline & $\begin{array}{l}\text { "Leading and } \\
\text { Collaborating } \\
\text { with } \\
\text { Colleagues" }\end{array}$ & $\begin{array}{l}\text { "Working } \\
\text { With } \\
\text { Students" }\end{array}$ & $\begin{array}{l}\text { "Planning } \\
\text { and } \\
\text { Analysis" }\end{array}$ & $\begin{array}{l}\text { "Content } \\
\text { Knowledge" }\end{array}$ & $\begin{array}{l}\text { "Philosophy } \\
\text { Towards } \\
\text { Teaching" }\end{array}$ \\
\hline $\begin{array}{l}\text { Observations } \\
\text { ( } \% \text { of total) }\end{array}$ & $2(5.9)$ & $10(29.4)$ & $10(29.4)$ & $8(23.5)$ & $4(11.8)$ \\
\hline Responses & $0(0.0)$ & $2(13.3)$ & $6(40.0)$ & $4(26.7)$ & $3(20.0)$ \\
\hline
\end{tabular}

More specifically, Teacher 3 spent her time in class engaged in the following activities:

- Anticipating student difficulties by giving detailed instructions before an activity or lesson began (categorized as "Working with Students")

- Learning about tools used on the boat that were new to her, or reviewing the plans and processes related to upcoming experiences, to make sure she was comfortable leading the lessons and activities of the day (categorized as "Planning and Analysis")

Detailed descriptions of observational instances that align with these actions, and how these promote student growth, can be found in Appendix K. During her interview, Teacher 3 more specifically mentioned that the following activities are important to being a teacher:

- Reviewing lesson plans and practicing with materials (categorized as "Planning and Analysis") 
- Being able to answer specific student questions about concepts (categorized as "Content Knowledge")

Teacher 3's response frequencies differed from observation data by greater than $10 \%$ in the "Leading and Collaborating with Colleagues," "Content Knowledge," and "Philosophy Towards Teaching" categories. Her response frequencies corresponded with the observation data within $10 \%$ in the "Working with Students" and "Planning and Analysis" categories.

Teacher 3 talked about the need for a teacher to recognize when a student was having trouble understanding a new idea. Like Teacher 1 and Teacher 2, Teacher 3 has had one teacher during her schooling that inspired her interest in teaching. She talked about her high school math teacher, who had an uncanny ability to recognize when his students did not understand a concept, and challenged the class to make their own meaning and be responsible for their peers.

Teacher 3 also has years of experience in working in restaurants, and because of this wealth of experience, she has often been in charge of training new employees, many of whom were new to the service industry in general. She said she found modeling and demonstrating effective techniques as a server was the most effective way to teach new employees, and said she thought it was effective in teaching other ideas as well.

More detailed descriptions of experiences Teacher 3 talked about in her interview, and how these promote student growth, can be found in Appendix L. 
When I scored both observations and interview responses on the PCK Rubric, Teacher 3 received a two out of four in the first domain (Knowledge of Student Thinking about Specific STEM Topics). This was primarily because she was able to recognize common misconceptions, but was not able to fully consider a student's thinking in a subject. Based on her experiences and training, she lacked background in discovering prior student knowledge.

Teacher 3 scored a two out of four in the second domain (Understanding and Use of the Effective Strategies for Specific STEM Topics) primarily because she exhibited a general understanding of a specific idea being challenging based on language or cognitive development. She lacked, however, a specific understanding of STEM topic difficulties based on grade level. Teacher 3's rubric score are included in Table 4.14 below:

Table 4.14 Teacher 3 PCK Rubric Scores:

Knowledge of Student Understanding and Use of Thinking about Specific the Effective Strategies for STEM Topics

a.) 2

b.) 2

c.)

d.)

e.) Overall Rubric Scale: $0=$ little to no evidence to $4=$ strong evidence Rubric available for review in Appendix A Specific STEM Topics

Teacher 1's fingerprint indicates that she values putting individual emphasis towards teaching each individual student. She also values planning and reflection time with her co-teachers. She brought her many experiences in informal education, as both a student and teacher. 
Teacher 2's fingerprint indicates a strong understanding of common misconceptions and knowledge of how to teach particular math concepts. Teacher 2 also confidently leads planning and implementation of lessons with his co-teachers. He brings a background of formal training as a licensed teacher to inform his practice.

Teacher 3's fingerprint also indicated that she both valued, and spent time thinking about how her students might be thinking. While she does not have formal training or much experience in working with students in math lessons, she has a strong passion for the work and does everything she can to be her best for her students.

\section{Student Perception of Teachers}

During the interviews, students were asked about their time with the Wind \& Oar Boat School, both related to the assessment task and the experience in general. Quantitative data from the interviews was reported previously as Table 4.5. It is reported again below because it is useful in helping to illuminate the students' perceptions of their teachers. Table 4.15 below includes student responses, and mentions of how they learned specific concepts they worked with throughout the week: 
Table 4.15 Student Interview General Responses:

\begin{tabular}{|c|c|c|c|c|}
\hline & "Intuition" & $\begin{array}{l}\text { "Prior } \\
\text { Knowledge" }\end{array}$ & $\begin{array}{l}\text { "Conceptual } \\
\text { Understanding } \\
\text { Unrelated to } \\
\text { Assessment" }\end{array}$ & $\begin{array}{l}\text { "Experience with } \\
\text { the Wind \& Oar } \\
\text { Boat School } \\
\text { Teachers" }\end{array}$ \\
\hline Student 1 & 1 & 0 & 4 & 5 \\
\hline Student 2 & 0 & 0 & 4 & 3 \\
\hline Student 3 & 0 & 3 & 1 & 5 \\
\hline Student 4 & 1 & 0 & 4 & 3 \\
\hline Student 5 & 1 & 0 & 4 & 5 \\
\hline Student 6 & 2 & 2 & 1 & 3 \\
\hline Student 7 & 1 & 0 & 1 & 4 \\
\hline Total & 6 & 5 & 19 & 28 \\
\hline
\end{tabular}

Students were also asked to elaborate if there were any specific things a teacher did, or any experience at Wind \& Oar that helped them on the post-test. The data show that students recognized learning from their teachers and the Wind \& Oar experience. Table 4.16 is included below, showing how many times a student mentioned a specific teacher, as well as how often any teachers were mentioned at all:

Table 4.16 Student Interview Mentions of Specific Teachers:

$\begin{array}{llll} & \text { Teacher } 1 & \text { Teacher 2 } & \text { Teacher 3 } \\ \text { Student } 1 & 1 & 3 & 1 \\ \text { Student 2 } & 1 & 0 & 1 \\ \text { Student 3 } & 3 & 3 & 3 \\ \text { Student 4 } & 2 & 2 & 1 \\ \text { Student 5 } & 2 & 2 & 2 \\ \text { Student 6 } & 0 & 0 & 0 \\ \text { Student 7 } & 1 & 1 & 0 \\ \text { Total Mentions } & 10 & 11 & 8\end{array}$

The number of times a student mentioned a teacher as being helpful was compared to the improvement in tests scores. Each teacher was assigned one point for each point of improvement in assessment score for the students that 
mentioned helpful experiences with that teacher. Table 4.17 shows total points assigned to each teacher using this method:

Table 4.17 Score Change Attributed to Teachers:

Conceptual

Knowledge

Assessment

Application of

Knowledge

Assessment

Overall

6
Teacher 2

1

3

4
Teacher 3

1

4

5

Student 3 mentioned specific teacher actions the most during her interviews, with nine instances. Student 5 followed at six instances, and then Student 1 and Student 4 at five instances each.

Student 3 Teacher Actions Interview Responses: During her interview, Student 3 mentioned that specifically practicing measuring angles and distances throughout the week was relevant to doing the Conceptual Knowledge task.

She also mentioned that she remembered using the tape measure to find the locations for the rails on the sides of the boat. This was a task she worked with Teacher 1 and Teacher 3, although throughout the week all three teachers reinforced these skills at different points.

Student 3 said that no particular instance that covered these topics was more relevant than any other, just that the reinforcement in general was good.

Student 5 Teacher Actions Interview Responses: During her interview, Student 5 mentioned specifically that doing the "Magic Inch" activity with Teacher 2 helped her with fractions and measuring. 
She also mentioned that the centerframe breaking during Day 4 was frustrating, and that she felt like she did not learn anything from this. However, later in her interview she said she thought that over the course of the class, she learned to think about what kinds of strain different parts of the boat are under. She thinks she has a better idea bout reinforcing those parts, which was a task she worked on with Teacher 1 when the centerframe did break.

Student 1 Teacher Actions Interview Responses: During her interview, Student 1 mentioned specifically doing practice with adding and subtracting fractions, as well as going through calculations for volume when working on model boats, helped her to understand math concepts. She thought that through direct practice and visual applications, she would be able to remember these concepts better. Both of these tasks were things she worked on with Teacher 2 .

Student 4 Teacher Actions Interview Responses: During her interview, Student 4 mentioned specifically practicing measuring angles on the stem with Teacher 2. She also said that the teaching style of Teacher 1 and Teacher 3 was particularly helpful, because she felt ok in speaking up when she didn't understand. She said she could tell that they would really want to help, they would be patient, and they were always nice while she learned. For her, being kind is the most motivating thing a teacher can do.

Students as a whole had something positive to say about each teacher. In compiling all student data, no negative interactions with or interview responses about any of the three teachers were observed. It does appear that a student's 
likelihood to talk about a positive interaction with a teacher does not directly related to their growth on this particular assessment, however.

Not only did students not have any negative interactions to report, they actively said that they felt that they had learned a lot throughout the week. For many of the students, having practice with concepts in math that was directly applicable to a task while building the boat was viewed as a way to remember the concept in the future.

The teachers should take note of where they use the inherent advantage at the Boat School with this hands-on project, and continue to reinforce those connections. Furthermore, they should look for other opportunities to introduce a mathematics connection into the boat building. In formal schooling, both positive and negative associations with math classes can be observed. However, neither during the class or post interview did students in this program complain about working on any math lesson. For both the math concepts they think students learn a lot about, and those that may not be reinforced well enough, efforts should be made to further tie any math instruction to the immediate applicability on the boat, since this is what many students noted as helpful and worthwhile compared to a conventional math class.

The teachers should also pay attention to the strategies they use to build relationships with their students, as the opportunities that were used were not lost on this class. Several students listed their positive interactions with the teachers as something they really enjoyed throughout the week. 
Although all of the students were female, and one of the three teachers for this class was male, there was no evidence collected that indicated a gender difference in how the students related to their teachers. While the student change on the assessments attributed to the teachers was lowest for the Teacher 2 , the explicit interview responses cited him most often as helpful throughout the week.

While one explanation could be that the students held a conscious bias for Teacher 2, and a subconscious bias against Teacher 2 , the observational data does not seem to indicate this. In almost all instances where students were allowed to choose a teacher to work with, they indicated verbally that they wanted to work with a certain tool that a teacher would be using for their project, and not that they wanted to work with that particular teacher personally.

Because the design of this project was not originally centered on the collection of data related to gender differences, and how this affected the teachers' interactions with their students, it is possible that any data indicating a difference was missed through the use of the research instruments I selected. However, the potential coverage of the observational protocol used was wide, so the lack of any observations indicating a gender difference is reassuring. Influence and Interactions Between Teachers

The Wind \& Oar Boat School uses co-teaching as an instructional model. Co-teaching involves two or more teachers adopting responsibility for the instruction of one group of students. This usually means that co-teachers take on different roles in a lesson, or that the classes are highly fluid, with several 
activities going on at any one time. It is also essential that co-teachers take on an equal responsibility for instruction; co-teaching is not one teacher making all of the decisions while another watches or acts as an aid. Examples of what coteaching can look like, as defined by Bacharach, Heck, \& Dahlberg (2010) are included in Table 4.18 Below: 
Table 4.18 Examples of Co-Teaching:

\begin{tabular}{|c|c|}
\hline \multicolumn{2}{|c|}{\begin{tabular}{|c|} 
Co-Teaching Model|Definition \\
\end{tabular}} \\
\hline Station Teaching & $\begin{array}{l}\text { Co-teachers divide content and students. Each teacher then } \\
\text { teaches the content to one group and subsequently repeats } \\
\text { the instruction for the other group. If appropriate, a third } \\
\text { "station" could give students an opportunity to work } \\
\text { independently. When more than two educators are } \\
\text { co-teaching, there can be one station for each teacher. }\end{array}$ \\
\hline Parallel Teaching & $\begin{array}{l}\text { The co-teachers are both teaching the same information, } \\
\text { but they do so to a divided class group. The teachers teach } \\
\text { the exact same lesson in the exact same way and use the } \\
\text { same materials. The purpose is to increase active student } \\
\text { engagement with a lower student-teacher ratio. }\end{array}$ \\
\hline $\begin{array}{l}\text { Alternative } \\
\text { Teaching / } \\
\text { Differentiated } \\
\text { Teaching }\end{array}$ & $\begin{array}{l}\text { The co-teachers are both teaching the same information, } \\
\text { but they do so to a divided class group. The teachers use } \\
\text { different approaches for presenting the content. The } \\
\text { purpose is to increase active student engagement with a } \\
\text { lower student-teacher ratio and to address the needs of all } \\
\text { learners using varied instructional approaches. }\end{array}$ \\
\hline $\begin{array}{l}\text { Team Teaching } \\
\text { (Teaming) }\end{array}$ & $\begin{array}{l}\text { Both teachers know and can deliver the material of the } \\
\text { lesson; "one script, two voices". Therefore, both teachers } \\
\text { share delivery of the same instruction to a whole student } \\
\text { group. Some refer to this as having "one brain in two } \\
\text { bodies". This is used when it is necessary to have two } \\
\text { teachers deliver the instruction at the same time (e.g., one } \\
\text { teacher presents visual supports while the other provides } \\
\text { verbal instruction, both teachers provide immediate } \\
\text { feedback during guided and independent practice, etc.). }\end{array}$ \\
\hline $\begin{array}{l}\text { Supplemental } \\
\text { Teaching }\end{array}$ & $\begin{array}{l}\text { One teacher takes responsibility for the large group while } \\
\text { the other works with a smaller group or an individual } \\
\text { student. Supplemental teaching can be used for } \\
\text { remediation, acceleration, pre-teaching, helping students } \\
\text { who have been absent catch up, assessment, etc. }\end{array}$ \\
\hline $\begin{array}{l}\text { One Teach-One } \\
\text { Observe }\end{array}$ & $\begin{array}{l}\text { Co-teachers decide in advance what types of specific } \\
\text { observational information to gather during instruction and } \\
\text { agree on a system for gathering the data. Afterward, the } \\
\text { teachers analyze the information together. This is referred } \\
\text { to as "observing with a focus". The observer observes the } \\
\text { students and/or the instructing teacher can to gather data. }\end{array}$ \\
\hline $\begin{array}{l}\text { One Teach-One } \\
\text { Assist }\end{array}$ & $\begin{array}{l}\text { One teacher has the primary responsibility for teaching } \\
\text { while the other teacher circulates through the room } \\
\text { providing unobtrusive assistance to students, as needed. }\end{array}$ \\
\hline
\end{tabular}

(Bacharach, Heck, \& Dahlberg, 2010) 
As these examples show, although each teacher might have a unique role in a lesson, each role should support the experience of the students in achieving a given lesson's goal. The Boat School teachers used almost every one of these approaches described by Bacharach, Heck, \& Dahlberg at one point during the week of this study. Examples of how the Boat School teachers used these strategies are included in Table 4.19 below:

Table 4.19 Boat School Co-Teaching Examples:

\begin{tabular}{|c|c|}
\hline $\begin{array}{l}\text { Co-Teaching } \\
\text { Model }\end{array}$ & Examples \\
\hline Station Teaching & $\begin{array}{l}\text { On the first day, students rotated between Teacher } 1 \text {, } \\
\text { Teacher } 2 \text {, and Teacher } 3 \text {, who each taught the technique and } \\
\text { safety requirements when using a specific tool. }\end{array}$ \\
\hline Parallel Teaching & $\begin{array}{l}\text { When teaching fractions and technique with a measuring } \\
\text { tape, Teacher } 1 \text { took one group of students, while Teacher } 2 \\
\text { and Teacher } 3 \text { worked to teach another group of students. }\end{array}$ \\
\hline $\begin{array}{l}\text { Alternative/ } \\
\text { Differentiated } \\
\text { Teaching }\end{array}$ & (Not observed) \\
\hline $\begin{array}{l}\text { Team Teaching } \\
\text { (Teaming) }\end{array}$ & $\begin{array}{l}\text { Teacher } 2 \text { and Teacher } 3 \text { designed and presented the } \\
\text { motivational component of the Laura Dekker lesson together. } \\
\text { At any given time in this lesson, these two teachers may have } \\
\text { been presenting to the whole group at the same time, may } \\
\text { have been going from student to student to check for } \\
\text { understanding, or splitting and recombining the groups to } \\
\text { have students share ideas. }\end{array}$ \\
\hline $\begin{array}{l}\text { Supplemental } \\
\text { Teaching }\end{array}$ & $\begin{array}{l}\text { When the centerframe broke on the fourth day, all three } \\
\text { teachers took a small group of students to work on projects } \\
\text { related to fixing the boat. These groups were selected based } \\
\text { on their skill with certain tools, for an extension of a } \\
\text { technique they already excelled with. }\end{array}$ \\
\hline $\begin{array}{l}\text { One Teach-One } \\
\text { Observe }\end{array}$ & (Not observed) \\
\hline $\begin{array}{l}\text { One Teach-One } \\
\text { Assist }\end{array}$ & $\begin{array}{l}\text { Teacher } 2 \text { and Teacher } 3 \text { also worked together on the scale } \\
\text { drawing component of the Laura Dekker lesson, but with a } \\
\text { different dynamic. Teacher } 3 \text { presented the overall idea and } \\
\text { method to the small group, while Teacher } 2 \text { rotated among } \\
\text { the students and helped any who seemed confused or stuck . }\end{array}$ \\
\hline
\end{tabular}


The teachers would employ a different co-teaching strategy for various reasons. Sometimes an approach would be implemented based on what they have seen in previous classes (learning the tools has been easier in small groups). At other times, an approach would be used because some students in this class had been struggling or needed an extension of a skill they had mastered (fixing the centerframe).

One example of this was evident on the second day, when Teacher 1 and Teacher 3 worked together to create an activity and motivational experience for the students. This was constructed based on the mission of Girls Inc. ("inspiring all girls to be strong, smart, and bold" (Girls Inc., 2016). At several points in the day before and day of these experiences, Teacher 1 and Teacher 3 talked about what they wanted to do, what they wanted students to get out of the experiences, and what they wanted to change after starting the activity with one group of the students.

Teacher 1 and Teacher 2 also worked together in the mornings to make sure that some parts got prepared for students to use that day, as well as that the tools were functioning properly. Teacher 1 said that she thought this was one of the most important preparation steps she took, so students using them would have a more positive experience.

When planned in advance, this was done in a collaborative way during the planning sessions each afternoon. When implemented in the moment, often Teacher 1 and Teacher 2 would collaborate to delegate roles, or Teacher 2 would 
delegate roles for everyone. When decided for immediate implementation, Teacher 2 was always involved.

While the Boat School did have it's own structure for how the teachers worked together, each had a set of unique approaches and attitudes, encompassed within their "fingerprint". Specific things a teacher thought or did that proved to be effective did end up being more common in observations of the other teachers later in the week.

Teacher 2 and Teacher 3 were observed adopting aspects of Teacher 1's practice. In particular, the enthusiasm for treating students as individuals with individual needs was seen more often with Teacher 2 and Teacher 3 later in the week. Each exhibited these behaviors more often on the fourth and fifth day than had been observed on the first, second, and third day. Table 4.20 below details actions similar to this observation for each teacher, organized temporally:

Table 4.20 Encouraging Different Learning Styles and Following Student Enthusiasm Observations, Change Over Time:

$\begin{array}{llllll} & \text { Day } 1 & \text { Day } 2 & \text { Day } 3 & \text { Day } 4 & \text { Day 5 } \\ \text { Teacher } 1 & 5 & 1 & 4 & 5 & 4 \\ \text { Teacher } 2 & 1 & 0 & 0 & 4 & 2 \\ \text { Teacher } 3 & 1 & 0 & 1 & 3 & 2\end{array}$

Teacher 1 and Teacher 3 were also observed adopting aspects of Teacher 2's teaching. In particular, trying and being able to anticipate what students will need to do next, and what problems they might have with new tasks or ideas, was observed more often in Teacher 1 and Teacher 3 later in the week, although 
still not as frequently as with Teacher 2 . Table 4.21 details actions similar to this observation for each teacher, organized temporally:

Table 4.21 Anticipating Steps or Trouble in a Task Observations, Change Over Time:

$\begin{array}{llllll} & \text { Day 1 } & \text { Day 2 } & \text { Day 3 } & \text { Day 4 } & \text { Day 5 } \\ \text { Teacher 1 } & 0 & 0 & 0 & 1 & 1 \\ \text { Teacher 2 } & 3 & 1 & 4 & 2 & 0 \\ \text { Teacher 3 } & 0 & 0 & 0 & 1 & 3\end{array}$

This aspect of Teacher 2's practice was of particular interest to this research, as this is a key component of PCK. Observing his influence on the other two teachers shows that co-teaching with more experienced educators can have a profound impact on an individual's PCK.

Modification to some of the aspects of Teacher 3's teaching was observed, facilitated through interactions with Teacher 1 and Teacher 2. In particular, attempting to give every detail concerning a task before beginning was something Teacher 3 relied on often at the beginning of the class, while employing other strategies became more common by the end.

Throughout this week, Teacher 1 was much more concise, while Teacher 2 employed a similar strategy at times. I noticed that the more time Teacher 1 and Teacher 3 spent working together, the less common it was for Teacher 3 to anticipate student difficulties using only verbal instruction.

The teachers all worked with students individually at some times, and in groups at other times. Most of the group-times saw Teacher 1 and Teacher 3 paired together, while Teacher 2 worked with students alone. This may have led to Teacher 3 adopting a multi-modal approach to anticipating student problems, 
similar to Teacher 1 . Tables 4.22 details actions similar to this observation for each teacher, organized temporally below:

Table 4.22 Giving Detailed Instructions Observations, Change Over Time

$\begin{array}{llllll} & \text { Day } 1 & \text { Day } 2 & \text { Day } 3 & \text { Day } 4 & \text { Day 5 } \\ \text { Teacher } 1 & 1 & 0 & 1 & 1 & 1 \\ \text { Teacher } 2 & 0 & 2 & 3 & 0 & 2 \\ \text { Teacher } 3 & 4 & 0 & 3 & 0 & 1\end{array}$

While unique and easily identifiable, each teacher shares similar behavioral observation frequencies with the others in certain categories. Teacher 1's and Teacher 3's total observation frequencies agree within five percentage points in "Leading and Collaborating with Colleagues" and ten percentage points in "Planning and Analysis". Teacher 2' and Teacher 3' total frequencies agree within five percentage points in both "Content Knowledge" and "Working With Students." All three teachers' total frequencies agree within five percentage points in "Philosophy Toward Teaching".

The greatest variations observed between teachers were in "Leading and Collaborating with Colleagues" (between Teacher 1 and Teacher 2 at a 20.2 percentage points different, and between Teacher 2 and Teacher 3 at a 24.1 percentage points different) and in "Working With Students" (between Teacher 1 and Teacher 3 at 18.2 percentage points different).

\section{Summary of Results}

\section{Statements About Students}

While some improvement was observed, the student data provide insufficient evidence at significance .05 to conclude that the student performance improved on either the post-test conceptual knowledge or 
application of conceptual knowledge tasks. Many of the students exhibited common mistakes in the assessments, in both the pre- and post-tests, suggesting a set of shared misconceptions. The raw output from the analysis software I used is included in Appendix M.

Students did have a lot to say about what they thought they got out of the instructional time at the Boat School. Observations of students, along with some of their interview responses, showed growth in student ability to accurately describe the role of principles of geometry in real-world project design. Some responses showed an increased use of vocabulary specific to geometry, scale, and woodworking after completing the Boat School class. Finally, other responses indicated that students were able to tap into prior knowledge of a concept to use this in their assessment task.

\section{Statements About Teachers}

Those teachers with a longer history in education, or with more specific teacher training were likely to score higher than their colleagues with a short history in education or with fewer formal teacher preparation experiences.

The teacher data also provided many examples of a collaborative work environment for teachers. Teacher 1 appeared to have the most influence on the style of the other teachers. Teacher 2 appeared to have the most experience, and while willing to try the strategies of other teachers needed to observe them more to do so. Teacher 3 was the most willing to learn from her peers.

Even in the one-week observation period, changes to instructional styles were observed in each teacher. Those teachers with higher efficacy, as scored on 
the PMSP PCK Rubric, were more likely to have styles that were emulated. The teachers with lower efficacy, as scored on the same rubric, were less likely to have their styles adopted, but were in fact more likely to change their styles to match those of their co-teachers.

An element of time or proximity my be related to a teacher adopting a new teaching style, as teachers that spent more time teaching side-by-side this week were more likely to exchange styles than those who worked independently more often.

Finally, in their reflections, each teacher from the Boat School mentioned at least one previous teacher as an influence on their interest and ability in teaching. The other responses varied from teacher to teacher about their inspirations for teaching style. Formal professional teacher training, experience in service industries, and informal teaching experiences all featured as influences. 


\section{Discussion}

\section{Student Assessment Data}

Students did not reach the level of improvement in their ability to do a scale drawing that I expected. The acceptance of the null hypothesis was surprising, based on the interview data gathered from the students about what they thought they learned, and what they found the most meaningful throughout the treatment.

On the other hand, the students did show an improved recognition of how geometry applies to design in the real world, a greater use of math and woodworking vocabulary, and a greater application of previously taught concepts. These qualitative data at least partially supported my hypothesis about student learning from a project-based curriculum. Why did students fail to improve their geometry skills?

After observing the planning and implementation of the instructors, as well as their interactions with students, I suspect that the limitations of this study's design; temporal, sample size, or lack of control group have impacted the accuracy of the results. While it is possible that some positive aspect was missing from instruction that affected the impact of the program, several aspects of the teachers' instructional styles tie directly to methods shown by research to lead to positive gains in students, so the former explanation seems more plausible. 
It is possible that students were not given adequate time thinking about and practicing scale and proportion concepts in similarly advanced formative experiences to be successful at the task used for assessment. The two assessment tasks consisted of executing the drawing, and differentiating the drawing from real part (the former categorized as a conceptual task at the Apply level and the latter as an application task at the Analyze level of Krathwohl's updated Bloom's taxonomy (2002)). Most of the students' practice with using scale and geometry concepts during the class was at the Remembering level for conceptual tasks, and the Applying level for application tasks.

During the course of the Boat School program, students were given one explicit lesson regarding doing a scale drawing, and one explicit lesson in using a scale drawing to build parts of the boat.

The scale-drawing lesson involved taking a photograph of Laura Dekker, the center of a motivational talk later in the day, splitting the image into twelve equal sections, and assigning each student to a section. The students then were given a lesson on how to grid out and draw a larger version of their section, without having seen the completed image yet.

The lesson in creating parts from a scale drawing took place once the general shape of the boat had formed. There were several framing pieces that needed to be created and mounted before additional structure could be added. Students were taught how to read the boat plans, scale up the measurements from the plans, and use those dimensions to create these frames. Out of the nearly forty hours of instructional time the students spent at the Boat School, 
these two lessons took about four hours. Additional practice time with using the plans to create parts may have added another hour to this total.

Students often benefit from "priming" when assessing new information (Ormell, 2005). This priming takes the form of some kind of warm-up or reminder of previous learning, before a new idea is introduced. Priming can also be used before administering an assessment to aid student application. Furthermore, geometry and scale concept knowledge has been shown to need much repetition (Hilton, 2013), so for future classes more time spent reviewing the ideas covered in this assessment would be beneficial.

\section{What changes were observed in students?}

Changes in other aspects of student understanding were observed, although not originally accounted for in the research proposal. Evidence of these changes was collected through the exploratory participant observation design.

Relation of Boat Design to Function: As part of the interview before and after the treatment, students were asked to relate the part of the boat they had drawn to how the boat functioned as a whole. In the pre-interview, no students made a connection to how the design of the particular part they were drawing could affect the structure or function of the boat as a whole. Six of the seven students made some mention of design of the stem and structure or function of the complete boat in their post-interview.

This question was not assessed for how well it addressed the metrics of the ACK rubric, and thus the responses were not scored using this tool. The responses, however, do appear to relate to the application of conceptual 
knowledge, as defined by the PMSP. The rubric scoring language includes the following, "Students can (frequently or consistently) give a valid conclusion based on the correct application of relevant science concepts" (PMSP, 2012). Many of the student responses related to applying math concepts to the design of specific boat parts were outside of the context of any experience at the Boat School. The students were able to "organize and interpret information" (Lingard, Mills, \& Hays, 2006, p.g. 94) in a highly individual way, indicating some contextualization and application of conceptual knowledge.

It would be interesting to explore this idea further with students, as there are many more pieces of this boat that relate to similar concepts. The shape of the centerframe, transom, and chine logs all also relate to the overall shape and size of the boat. The chine logs and transom also relate to available surface area to attach the bottom to the boat, increasing the robustness of the junction here.

I suspect that students would be able to relate the same concepts to the structure and function of each of these parts of the boat, and to describe the impacts any changes to these components would have.

Increased Student Use of Math and Woodworking Vocabulary: Students were also observed incorporating new vocabulary learned throughout the week. These changes were observed in both math language as well as wood-working language. Students were also able to describe their methods in more detail in the post-interview. No formal lessons were given in woodworking or math vocabulary, so any understanding gained by students was done by the use of academic language in context throughout the week. 
Research seems to indicate that instruction connecting different ideas mathematics is not the norm. Stigler \& Hiebert (1999) state plainly, "What we can see clearly is that American mathematics teaching is extremely limited, focused for the most part on a very narrow band of procedural skills...they spend most of their time acquiring isolated skills through repeated practice" (10-11).

An understanding of math vocabulary is directly tied to student conceptual understanding of correlated math concepts (Dunston \& Tyminski, 2013). Increasing a student's understanding of vocabulary helps them to bridge the gaps between ideas that seem disconnected at first. Furthermore, connecting old and new ideas in math are directly tied to higher-level thinking (Rubenstein, 2007).

More specifically, Stahl and Fairbanks (1986) postulated that student achievement in mathematics would increase by at least one-third if specific words that are important to a student's learning were emphasized. Clearly, vocabulary gains can be more important than they appear at first glance, and the preliminary data we have gathered about the Boat School in this study are intriguing.

Evidence of Application of Prior Knowledge: Another common yet unexpected pattern to the responses was that more students mentioned thinking about things they had learned in their traditional classrooms in the past while doing the post-test than did during the pre-test. While the Boat School may not have taught those students a completely new concept, seeing the application in 
the real world allowed them to contextualize previously experienced concepts in a real-life setting.

I was not able to find any research linking project-based learning to increased contextualization of prior knowledge in students. However, the work of Raes and Schellens (2016) showed that highly-structured interventions in a project-based computer class for students of various experience levels, led to less frustration among students with lower levels of prior knowledge.

The descriptions of computer classroom interventions in the Raes and Schellens study mirrored the structure of interventions at the Boat School with scale and geometry. Several Boat School students mentioned that they thought the teachers knew what they were talking about, were responsive to student needs, and encouraging when a student needed help.

\section{Teacher Observation Data}

Data from the teacher observations and interviews supported my hypothesis, that overall amount of experience teaching would correlate with the most developed PCK. Through several approaches to co-teaching, the influence of the teachers on one another when working on this project was also observed. Several patterns also emerged when talking with the students about how the teachers presented material in a way that addressed specific student problems. The students also noted ways the teachers had fostered positive relationships throughout the class.

How is a teacher's experience related to their PCK? 
The three Boat School teachers inhabit very specific niches due to their experience. Each of these teachers has a unique "instructional fingerprint", an identifiable combination of actions and philosophy towards students, constructed from their observations and responses. This "fingerprint" is unique, and would be easily identifiable in future observations with these teachers. This fingerprint is, at least in part, constructed through a teacher's previous experiences.

The more any teacher knows about what their students are already thinking, the better they will be able to address existing misconceptions directly. One observed difference between the formal and informally trained teachers was their specific knowledge of student thinking and common misconceptions in math and science. The development of these understandings is ongoing in most practicing teachers. These understandings are important to any STEM teacher, as students cannot often contextualize a new idea without first having their preconceptions addressed in a straightforward manner (Resnick , 1983).

Students did take note of the teachers' individual approaches, and either directly or indirectly commented on how central aspects of each teacher's "fingerprint" were helpful to them. Student 5 specifically mentioned the positive and nurturing teacher attitudes. Other students noted several activities shared between the teachers. Student 1 mentioned the multi-modality of the lessons, while Student 7 talked about how prepared and knowledgeable the teachers were. 
Odiri (2011) found that students observe and mimic a teacher's disposition. This will eventually play into their progress with learning. The attitude of a teacher must be positive to influence their student to greater achievement. He concluded by recommending workshops on positive teacher attitudes. This corresponds most heavily with several experiences Teacher 1 mentioned in her interview as influences on her teaching. She said, "my foundations woodworking course is always in mind. They were always careful about introducing new vocabulary, new ideas, new methods, and supporting their students. I want to be able to do that for others."

Ulug, Ozden, and Eryilmaz (2011) noticed in their preliminary study that positive teacher attitudes corresponded with positive student attitudes and greater gains in student personality development. Again, this ties in with the comments made by Student 5, that the most important thing for her is that "a teacher is nice and I can tell that they want to help me."

All three teachers used multiple representations for the ideas they presented at different times. When Teacher 1 was describing verbally what was causing a student's problem with the saw, she was also physically sawing using both proper and improper techniques. Teacher 2 had students fold paper into boxes representing boats, at specific side to bottom ratios. While he was doing that, he calculated the volume of the hypothetical boats. Teacher 3 taught students about scale factors while having them create drawings using the same ideas. 
Zhang (2016) showed that multimodality when teaching is an effective method for English language learners to bridge the gap between basic beginner language, and scientific and academic language. This also seems to speak to the developmental state of these particular students in this study. The transition from Concrete Operational to Formal Operational Stages begins around the same age as most of the students in this study. This transition is marked by a greater use of abstract and evidence-based thinking. Students in this transition, however, often need to revert to a simpler example or pattern of thinking when first presented with a new idea (Piaget, 1970).

It is unclear if the specific experiences each of the observed teachers could have a different impact size. Would we have seen similar scores between Teacher 1 and Teacher 2 on the rubric, if only Teacher 1 had slightly more experience regardless of type? Or would she have needed some formal, targeted teacher training to achieve the same rubric score? All this study can say is that more experience in general improves a teacher's PCK.

Additionally, it is not clear is if each teacher's "fingerprint" is generalizable to other teachers with similar backgrounds. These descriptions of teacher readiness are overly simplified, and do not fully describe the wealth of background each brings to the field. Would any experienced, informally trained teacher have a similar "fingerprint" to Teacher 1 ?

Collaboration on curriculum design can lead to active learning in teachers of ways to apply new ideas in the classroom. This professional development can 
happen in a fairly short time period, and also contributes to "meaningful, taskoriented collaboration" (Drits-Esser \& Stark, 2015).

Several instances of structured co-teaching (as defined by Bacharach, Heck, \& Dahlberg, 2010) were also observed throughout the week. Once student needs were identified, the Boat School teachers employed various co-teaching models.

Working in close proximity to one another, the three teachers of this research followed the pattern outlined in previous research. Those teachers working collaboratively more rapidly develop their instructional style and PCK, as models of change are more apparent.

\section{Boat School Structure}

The Boat School itself also seems to align to modern research on aspects of an affective educational program. The Framework for K-12 Science Education (National Research Council, 2012) states that instruction should build a student's knowledge and prepare them to modify their understanding in the future.

In their research, Harris et al. (2015) based their definition of effective science curriculum on this NRC Framework document criteria. The researchers summarized the intent of the new standards as: "science is not just a body of knowledge but also a set of practices for investigating, modeling, and explaining phenomena in the natural world."

With this guiding definition, Harris et al. set out to measure the impact of a specific project-based learning curriculum on student gains in science 
concepts. They found that in both physical and Earth science curriculums using a project-based foundation, students achieved significant gains compared to a control group. The curriculum for the Harris et al. research study was implemented in traditional classrooms, during the school day, in an urban school district. This context is much different from the informal setting of the Boat School in a local makerspace, over the summer with a summer enrichment program partner.

While the differences do not make a direct comparison possible, the Harris et al. research provides a proof of concept. Their research provides a framework for project-based programs to model themselves after to promote greater growth in the domain of conceptual knowledge in their pupils.

Regarding the structure of Boat School instructional time, Student 1 said, "Doing the math this way was good because we used it, and not just having a random lesson and then a test." Her comments also align with the Harris et al. (2015) research.

Recommendations for Boat School: There are several aspects that the Boat School should focus on for further development of the program.

First, the development and use of explicit learning targets for the various lessons and experiences through a boat build would help significantly to make expectations known to students, and ensure that all of the limited instructional time is adequately focused. The teachers do each individually have ideas about how their instruction aligns with the program goals, and the teachers do collaborate on curriculum design, the last bit of structured targets would allow 
sharing of transparent goals between each teacher, and the teachers and students.

Next, the Boat School should do further research and training with collaborative curriculum design and co-teaching models. These two instructional tools are informally used, but further understanding about how they support teacher development and student growth will allow them to be used more effectively.

The teachers at the Boat School should also spend more time learning and exchanging ideas about specific common student misunderstandings. Teacher 2 did exhibit this behavior at times, but this information did not always inform the practice of Teacher 1 and Teacher 3. For those misconceptions Teacher 2 already has an idea about, time should be spent to help Teacher 1 and Teacher 3 understand the difficulty there. All three teachers, however, should also spend more time researching and probing their students for other misconceptions related to the work of the Boat School.

To support these goals, the Boat School should also build in more structured planning and post-analysis time for each group of teachers at each class. Several of the teachers in this research project mentioned that they thought this time was invaluable, and that they missed in when it did not happen. If the collaborative curriculum design and co-teaching is to be explored further, having this time set aside will facilitate this development.

Finally, one strength of the Boat School is the diversity of experience in their teachers. Each student was able to identify and connect with each teacher 
on a different level based on his or her different experiences and attitudes.

Diverse role models can inspire students to achieve in a field, even if they feel like they don't fit in at first. Additionally, the diversity of the teachers allowed for many approaches to any student issues, further supporting an equally diverse student base.

Notes on Use and Modification of Research Instruments: While Teacher 2 scored higher than Teacher 1 on the PCK Rubric, students that showed the most improvement on the post-test more often cited Teacher 1 as being the most helpful. This may point to adjustments necessary to the PCK Rubric to incorporate student perceptions, or may indicate that although positive attitudes are important for student outcomes, solid pedagogy has more of an impact on student outcomes.

In designing a research question using the ACK Rubric to assess student performance, the ACK Rubric is lacking some clear guidance about how different types of tasks might more specifically be assessed. The PMSP has produced descriptions of types of ACK tasks, but these do not seem to directly inform the Rubric criteria. Time spent aligning these two documents would allow for greater ease of use for researchers wanting to use this instrument in the future.

While the somewhat open structure of the ACK Rubric felt confusing, a similar approach to the PCK Rubric did allow for was a very exploratory study into these three teachers. My perception of PCK as a construct is much wider than it was before beginning this study. While how a teacher interacts with a 
student is important, there are important distinctions between instructional practices and PCK.

If the Rubric were to be modified to add some weight to student perceptions, it might be to include their understanding that a teacher was using individualized strategies to support their learning and address their unique misconceptions.

The development of the idea of an "instructional fingerprint" speaks to the complexity of PCK, and the important differences to practice. PCK entails what a teacher knows and does to teach, as well as their understanding of student thinking, anticipation of prior misconceptions and how to address them, and as observed in this study, their philosophy towards teaching and students, as this shades every preceding feature.

\section{Limitations}

The first limitation to this study was the sample size and gender composition of students involved in the program. These factors were present due to the partner group Girls Inc., which agreed to take part in the study during their time with Wind \& Oar. Additionally, the Boat School usually works on a short timeline for finding partners with projects, so a class running concurrently was not available to build the sample size or expand the diversity of the sample.

The small sample size limited the ability to determine any statistically significant relationships in the data, due to lack of confidence in how representative this group is of the larger population (Trochim, 2006). Both the sample size and the gender composition of the students involved limited the 
generalizations that could be made about a wider population that the findings of this study could apply to (Trochim, 2006).

This study was also affected by the lack of a control group in the sample. Control groups allow research to be compared to a baseline measurement that has not been affected by any treatment. This comparison can be telling as to whether any change observed in the control group is due to the treatment being studied, or some other factor. Since the number of students participating was so small, I chose to observe the program as a whole, rather than limiting some students' access to the treatment. Without a control group, the results could have been affected by cultural, environmental, and other factors (Green \& Emerson, 2010).

Finally, this study is limited by the measures used to analyze the data. The student results of this study were analyzed using modified research instruments, originally developed by the Portland Metro Stem Partnership (PMSP). I started with instruments developed by the PMSP using research articles, and added some language to relate more to the task required of students. These changes were made to aid in consistency of scoring the student data.

All efforts were made to only add language that clarified how to score data in this particular instance. Changes to the instruments were made, however, which is worth noting. These additions may warrant further research in a larger pilot study, to verify the instrument is accurately measuring what I have used it to measure (International Testing Commission, 2005). 
I also used an observational protocol, outlined by de Walt \& de Walt (2002), for the teachers that may not have provided equal weight to each observational category. The observational protocol I used allowed me to observe and participate as both a teacher and a student during the course of the Boat School program. I purposely chose to go into the research with a totally open mind about what I would observe, to not unintentionally bias the data I collected.

The iterative process taking place after conducting the research could be seen as a limitation, as Philosophy Towards Teaching at best is difficult to observe in the classroom, if not impossible. Had this been outlined at the beginning, it would have been possible to be more vigilant for actions that align. Recommendations for Further Research

The Wind \& Oar Boat School was chosen for this research study largely for their unique mix of conceptual and practical approaches to math education. This includes the diverse history of instructors, flexible format, and use of a goaloriented project to design curriculum around.

While data was collected during the participant observation phase of this research pertaining to each of these aspects, not every aspect of the program was examined in depth. Incomplete data, as well as results that cannot be fully explained, leave the door open for further research.

Increased Sample Size with Control Group Included: The most obvious extension of this research is to expand the research sample, and include a control group with which to compare. The small sample size, with no control 
group presents several limitations to the generalizability of this research project. The proposed research design would be more robust, and allow a greater degree of certainty to the results.

Influence of a Shared, Formal Reflection Time: One unmeasured aspect of the teacher observations is the impact of the group reflection time on their teaching style. For Teacher 1, this was mentioned as an integral part of her teaching experience at the Boat School. The other teachers also mentioned this as being important to how they planned this class, and learned or practiced what they would be teaching. Were the Boat School teachers actually more effective in their job because they had this time, or is there actually no difference?

The research of Saito and Atencio (2016) shows that observations of other teachers teaching, as well as personal reflection time, are tied with development of PCK in a master teacher in Japan. This reflection time was solely individual, and so it is not clear if the same benefit would be observed when teachers reflect together.

Influence of Prior Teachers: In their reflections, each teacher from the Boat School mentioned at least one teacher they had while in school themselves. It is unclear through my search of the literature if this is a common theme, or if this is unique among this subset of teachers.

Further research could tell us if this theme of looking up to previous teachers is common across the population in general, or are those whose lives are impacted by their teachers more likely to become teachers, or pursue academic careers, themselves? 
Influence of Co-Teachers: Another unique aspect of the Wind \& Oar Boat School is their flexibility to assign several teachers to a lesson that requires that much instruction, and then move those teachers to other tasks when the situation changes in the day. This means that each of the teachers works with everyone else in the group intensively, and thus they are exposed to a variety of teaching styles over the course of a project.

The data collected points to a shift in each teacher's teaching style, based on their exposure to one another. This shift did not represent an entire overhaul to their teaching style, but a more subtle use of very specific behaviors that were previously observed very commonly in their peers.

Research has shown the effectiveness of co-teaching on student outcomes, but not on teacher development. Further research into interplay between teachers that work together frequently, whether teachers with certain backgrounds are more likely to be influential on their peers, if certain methods are more likely to be adopted, or if aspects of a teacher's personality create influence with their peers are all potential avenues.

\section{Conclusion}

Before this study, I had a much narrower focus of what PCK would look like. I know that PCK is not so simply tied to a teacher as a work title, but as a lens through which to view students, school, and learning more broadly. This is also heavily influenced by past experience as well as training, so there are many subjective influences to any one teacher that are not shared by all teachers. 
While there are some commonalities, a teacher with well-developed PCK need not be exactly the same as another similarly advanced teacher.

It is now more apparent to me that an effective teacher need not fit one definition, but might employ a variety of strategies, background knowledge, and personal experience to help their students. Additionally, what one teacher does may not work for all students, so a wealth of alternative approaches can be beneficial.

In my professional goals as a teacher, I will look for development opportunities from a variety of sources, and be sure to focus on developing my own understanding of what my students already think or know about a subject before beginning with new ideas. 
References

Bacharach, N., Heck, T. W., \& Dahlberg, K. (2010). Changing the face of student teaching through coteaching. Action in Teacher Education, 32:1, 3-14.

Ball, D. L., Hill, H. C., Bass, H. (2005). Knowing mathematics for teaching: who knows mathematics well enough for teach third grade and how can we decide? American Educator, 14-22 43-46.

de Walt, K, M. \& de Walt, B. R. (2002). Participant observation: Basic guide. Lanham, Maryland: AltaMira Press.

Drits-Esser, D., Stark, L. A. (2015). The impact of collaborative curriculum design on teacher professional learning. Electronic Journal of Science Education, 19:8, 1-27.

Dunston, P. \& Tyminski, A. (2013). What's the big deal about vocabulary? Mathematics Teaching in the Middle School, 19:1, 38-45.

Gallagher, J. J. (2000). Teaching for understanding and application of science knowledge. School Science and Mathematics, 100:6, 310-318.

Girls Inc. (2016). Goals and about. Retrieved from http://www.girlsinc.org/about/about-girls-inc.html

Green, K. H., Emerson, A. (2010). Mathematical reasoning in service courses: why students need mathematical modeling problems. The Montana Mathematics Enthusiast, 7:1, 113-140.

Han, S. Y., Carpenter, D. (2014). Construct validation of student attitude toward science, technology, engineering, and mathematics project-based learning: The case of Korean middle grade students. Middle Grades Research Journal, 9:3, 27-41.

Harris, C. J., Penuel, W. R., D’Angelo, C. M., DeBarger, A. H., Gallagher, L. P., Kennedy, C. A., Cheng, B. H., Krajcik, J. S. (2015). Impact of project-based curriculum materials on student learning in science: Results of a randomized controlled trial. Journal of Research in Science Teaching, 52:10, 1362-1385.

Hilton, A., Hilton, G., Dole, S., Goos, M., (2013). Development and application of a two-tier diagnostic instrument to assess middle-year students' proportional reasoning. Math Education Research Journal, 25, 523-545. 
International Test Commission, 2005. ITC guidelines for translating and adapting tests. Verson 1.0.

Jegede, O., Taplin, M., \& Chan, Sing-Lai (2010). Trainee teachers' perception of their knowledge about expert teaching. Educational Research, 42:3, 287308.

Kanter, D. E. (2009). Doing the project and learning the content: designing project-based science curricula for meaningful understanding. Wiley InterScience, Online.

Kanter, D. E., Schreck, M. (2006). Learning content using complex data in projectbased science: an example from high school biology in urban classrooms. New Directions for Teaching and Learning, 108, 77-91.

Kata, M., Master B., \& Yoon, C. (2015). Examining the early impacts of the Leading Educators Fellowship on student achievement and teacher retention. Rand Research Reports.

Krathwohl, D. R. (2002). A revision of Bloom's taxonomy: An overview. Theory into Practice, 41:4, 212-219.

Lingard, B., Mills, M., \& Hayes, D. (2006). Enabling and aligning assessment for learning: Some research and policy lessons from Queensland. International Studies in Sociology of Education, 16:2, 83-103.

Liu, L. O., Lee, H. S., Linn, M. C. (2011). Measuring knowledge integration: validation of four-year assessments. Journal of Research in Science Teaching, 48:9, 1079-1107.

Loo, Sai. (2012). The application of pedagogic knowledge to teaching: a conceptual framework. International Journal Lifelong Education. 31:6, 705-723.

Mielke, T. L., Rush, L. S. (2016). Making relationships matter: Developing coteaching through the concept of flow. English Journal, 105:3, 49-54.

Nason, R., Chalmers, C., Yeh, A. (2012). Facilitating growth in prospective teachers' knowledge: Teaching geometry in primary schools. Journal of Math Teacher Education, 15, 227-249. 
National Research Council (2012). A Framework for K-12 Science Education: Practices, Crosscutting Concepts, and Core Ideas. Committee on a Conceptual Framework for New K-12 Science Education Standards. Board on Science Education, Division of Behavioral and Social Sciences and Education. Washington, DC: The National Academies Press.

Odiri, O. E. (2011). The influence of teacher's attitude on students' learning of mathematics in Nigerian secondary schools. Journal of Research of Education and Society, 2:1, 15-21.

Ormell, C. (2005). Application readiness in maths, an essential concept. Journal of Science and Mathematics Education in S.E. Asia, 28:2, 73-80.

Piaget, J. (1970). Science of education and psychology of the child. New York City, New York: Orion Press.

Portland Metro STEM Partnership (2012). Application of conceptual knowledge rubric. Portland, Oregon.

Portland Metro STEM Partnership (2012). Pedagogical content knowledge rubric. Portland, Orgon.

Raes, A., Schellens, T. (2016). The effects of teacher-led class interventions during technology-enhanced science inquiry on students' knowledge integration and basic need satisfaction. Computers \& Education, 92, 125141.

Resnick, L. B. (1983). Mathematics and science learning: A new conception. Science, 220:4596, 477-478.

Rubenstein, R. (2007). Focused strategies for middle-grades mathematics vocabulary development. Mathematics Teaching in the Middle School, 13:4, 200-207.

Saito, E., Atencio, M. (2016). Pedagogical content knowledge in action: Its impromptu development by an expert practitioner. Pedagogy, Culture, \& Society, 24:1, 101-122.

Saxton, E., Burns, R., Holveck, S., Kelley, S., Prince, D., Rigelman, N. \& Skinner, E. A. (2014). A common measurement system for k-12 STEM education: adopting an educational evaluation methodology that elevates theoretical foundations and systems thinking. Studies in Educational Evaluation, 40, 18-35. 
Shulman, L S. (1987). Knowledge and teaching: foundations of the new reform. Harvard Educational Review, 57:1, 1-22.

Stahl, S. A. \& Fairbanks, M. M. (1986). The effects of vocabulary instruction: A model-based meta-analysis. Review of Educational Research, 56:1, 72-110.

Steele, M. (2013). Exploring the mathematical knowledge for teaching geometry and measurement through the design and use of rich assessment tasks. Journal of Mathematics Teacher Education, 16, 245-268.

Stern, L., Ahlgren, A. (2002). Analysis of students' assessments in middle school curriculum materials: aiming precisely at benchmarks and standards. Journal of Research in Science Teaching, 39:9, 889-910.

Stigler, J. \& Hiebert, J. (1999). The teaching gap, best ideas from the world's teachers for improving education in the classroom. New York, NY: Free Press.

Trochim, W. M. K. (2006). Social research methods knowledge base. Retrieved from http://www.socialresearchmethods.net

Ulug, M., Ozden, M. S., Eryilmaz, A. (2011). The effects of teachers' attitudes on students' personality and performance. Procedia-Social and Behavioral Sciences, 30, 738-742.

van Driel, J. H., Verloop, N., de Vos, W. (1997). Developing science teachers' pedagogical content knowledge. Journal of Research in Science Teaching, 35:6, 673-695.

Wilson, S. M., Floden, R. E., Ferrini-Mundy, J. (2002). Teacher preparation research: An insider's view from the outside. Journal of Teacher Education, 53:3, 190-204.

Zhang, Y. (2016). Multimodal teacher input and science learning in a middle school sheltered classroom. Journal of Research in Science Teaching, 53:1, 7-30. 


\section{Appendices}

\section{Appendix A: Portland Metro Stem Partnership PCK Rubric}

\begin{tabular}{|c|c|c|c|}
\hline & $\begin{array}{l}\text { Knowledge of student thinking about } \\
\text { specific STEM topics including prior } \\
\text { knowledge, misconceptions, learning } \\
\text { progressions, common difficulties, and } \\
\text { developmentally appropriate levels of } \\
\text { understanding. In planning, } \\
\text { implementation, and/or reflection the } \\
\text { teacher demonstrates: }\end{array}$ & $\begin{array}{l}\text { Understanding and use of the effective } \\
\text { strategies for specific STEM topics } \\
\text { including strategies to engage students in } \\
\text { inquiry, represent STEM phenomena, and } \\
\text { guide discourse about the STEM topic. In } \\
\text { planning, implementation, and/or } \\
\text { reflection the teacher demonstrates }\end{array}$ & \\
\hline 4 & $\begin{array}{l}\text { a) Sophisticated understanding of student } \\
\text { prior knowledge including misconceptions } \\
\text { and common learning difficulties; this level } \\
\text { of understanding includes student thinking } \\
\text { from multiple experiences in and out of } \\
\text { school as the basis of learning. } \\
\text { b) Careful consideration of the specific } \\
\text { STEM topic based on the grade level of } \\
\text { students, learning progressions, and } \\
\text { developmentally appropriate levels of } \\
\text { understanding, which reveals an } \\
\text { understanding that the specific idea is } \\
\text { challenging depending on grade level of } \\
\text { students. }\end{array}$ & $\begin{array}{l}\text { c) Many, diverse strategies including inquiry } \\
\text { strategies to challenge student thinking or } \\
\text { resolve learning difficulties about the specific } \\
\text { STEM topic. } \\
\text { d) Sophisticated understanding of } \\
\text { representations that are specific to the STEM } \\
\text { topic, pedagogically effective, accurate, and } \\
\text { strongly- linked to students' prior knowledge } \\
\text { and experience. } \\
\text { e) Language use around the specific STEM } \\
\text { topic includes multiple modes of } \\
\text { communication, an emphasis on students } \\
\text { communicating reasoning with many } \\
\text { questions clearly designed to probe for } \\
\text { student understanding of the specific STEM } \\
\text { topic. }\end{array}$ & 4 \\
\hline 3 & $\begin{array}{l}\text { a) Adequate understanding of student prior } \\
\text { knowledge including misconceptions and } \\
\text { common learning difficulties; this level of } \\
\text { understanding includes specific examples of } \\
\text { possible student thinking as well as ways to } \\
\text { look for that student thinking by listening to } \\
\text { students, reading students' work, etc. } \\
\text { b) Some consideration of the specific STEM } \\
\text { topic based on the grade level of students } \\
\text { and developmentally appropriate levels of } \\
\text { understanding, which reveals an } \\
\text { understanding that the specific idea is } \\
\text { challenging to students of a certain age or } \\
\text { when they don't have enough background } \\
\text { knowledge to understand. }\end{array}$ & $\begin{array}{l}\text { c) Some inquiry strategies to challenge } \\
\text { student thinking or resolve learning } \\
\text { difficulties about the specific STEM topic. } \\
\text { d) Adequate understanding of representations } \\
\text { that are specific to the STEM topic, } \\
\text { pedagogically effective, accurate, and well- } \\
\text { linked to students' prior knowledge. } \\
\text { e) Language use around the specific STEM } \\
\text { topic includes some variety in terms of modes } \\
\text { of communication (i.e. discussion (possibly in } \\
\text { groups of various sizes) and writing (e.g., } \\
\text { journals) for students to describe their ideas } \\
\text { and explain their thoughts about the specific } \\
\text { STEM concept) with some questions designed } \\
\text { to probe for student understanding of the } \\
\text { specific STEM topic. }\end{array}$ & 3 \\
\hline 2 & $\begin{array}{l}\text { a) Narrow understanding of student prior } \\
\text { knowledge including misconceptions and } \\
\text { common learning difficulties; this level of } \\
\text { understanding includes primarily } \\
\text { consideration of wrong } \\
\text { ideas/misconceptions or vague assumptions } \\
\text { about student thinking. } \\
\text { b) Limited consideration of the specific } \\
\text { STEM topic based on the grade level of } \\
\text { students or developmentally appropriate } \\
\text { levels of understanding, which reveals a } \\
\text { general understanding of the specific idea }\end{array}$ & $\begin{array}{l}\text { c) Few inquiry strategies to challenge student } \\
\text { thinking or resolve learning difficulties about } \\
\text { the specific STEM topic; those strategies } \\
\text { planned are not diverse strategies. } \\
\text { d) Narrow understanding of representations } \\
\text { that are specific to the STEM topic; planned or } \\
\text { implemented representations are } \\
\text { pedagogically limited, underdeveloped, } \\
\text { and/or weakly linked to students' prior } \\
\text { knowledge. } \\
\text { e) Language use around the specific STEM } \\
\text { topic is somewhat limited including whole }\end{array}$ & 2 \\
\hline
\end{tabular}




\begin{tabular}{|c|c|c|c|}
\hline & $\begin{array}{l}\text { being challenging because of vocabulary or } \\
\text { abstractness. }\end{array}$ & $\begin{array}{l}\text { class discussion, reading textbooks, or writing } \\
\text { reports or summaries with few questions } \\
\text { designed to probe for student understanding } \\
\text { of the specific STEM topic. }\end{array}$ & \\
\hline 1 & $\begin{array}{l}\text { a) No understanding of student prior } \\
\text { knowledge including misconceptions and } \\
\text { common learning difficulties, the } \\
\text { assumption that students have no prior } \\
\text { beliefs beyond what was taught in school, or } \\
\text { an awareness of prior knowledge but no } \\
\text { clear incorporation into lessons. } \\
\text { b) No consideration of the specific STEM } \\
\text { topic based on the grade level of students or } \\
\text { developmentally appropriate levels of } \\
\text { understanding, which reveals an assumption } \\
\text { about the specific idea not being challenging } \\
\text { for students or challenges being the same } \\
\text { challenges teachers themselves had as } \\
\text { students. }\end{array}$ & $\begin{array}{l}\text { c) Limited strategies and no inquiry strategies } \\
\text { to challenge student thinking or resolve } \\
\text { learning difficulties about the specific STEM } \\
\text { topic. } \\
\text { d) Limited or no understanding of } \\
\text { representations (i.e. illustrations, examples, } \\
\text { models, analogies, and demonstrations) that } \\
\text { are specific to the STEM topic; planned or } \\
\text { implemented representations are ineffective, } \\
\text { inaccurate, and/or not linked to students' } \\
\text { prior knowledge. } \\
\text { e) Language use around the specific STEM } \\
\text { topic is limited to teacher directed instruction } \\
\text { and student-student talk is not included or no } \\
\text { questions designed to probe for student } \\
\text { understanding of the specific STEM topic. }\end{array}$ & 1 \\
\hline
\end{tabular}


Appendix B: Discrete Teacher Actions Sorted by Category Type

Leadership of and Collaboration with Colleagues

- Directed other teachers during class - Planned a lesson for the collective group

- Planned a lesson for another teacher - Supported other teachers

- Organized efforts of non-teachers

Work with Students

- Led lesson

- Ensured all students were engaged

- Ensured all students were included - Suggested a specific method to a student

- Responded positively to a student error - Made sure a student actually understood

- Allowed students to explore - Encouraged hard work not only

result

- Encouraged different learning styles

- Connected concepts

- Promoted equality in the classroom

- Awareness of students' starting points

- Checked in with students

- Allowed wait time

- Called on students

- Confident in front of student

- Asked a question when students asked questions

- Modified instruction when an approach was not appearing to work

- Recognized and met students at their level

- Tied activities and experiences to concepts

- Emphasized student centered or student directed learning

- Anticipated misconceptions or student problems

- Allowed students to explore or following passions or interests

- Attended to individual student needs

Planning and Post-Analysis

- Planned a lesson

- Analyzed a lesson after class

- Focused on progress of bigger task

- Reflected on individual student levels

- Prepared for class

- Designed authentic tasks

- Allocated resources

- Maintained tools

- Paid attention to individual students' limitations

- Abstract thinking towards problem solving

Content Knowledge

- Maintained a high level of conceptual understanding

- Planned for or reflected about details of a concept

- Reviewed to prepare for class

Philosophy of Teaching 
- Had confidence in a teacher's role

- Formal preparation to be a teacher
- Belief students can make progress 


\section{Appendix C: Portland Metro Stem Partnership Application of Conceptual Knowledge Rubric}

\begin{tabular}{|c|c|c|c|}
\hline & Demonstration of conceptual understanding & $\begin{array}{l}\text { Application of conceptual knowledge: } \\
\text { Apply powerful disciplinary ideas, which } \\
\text { organize and interpret information and } \\
\text { evaluate them in new contexts. }\end{array}$ & \\
\hline 4 & $\begin{array}{l}\text { Student is able to explain/describe thoroughly } \\
\text { all relevant concepts utilizing all appropriate } \\
\text { vocabulary. }\end{array}$ & $\begin{array}{l}\text { Students can consistently give a valid } \\
\text { conclusion based on the correct application } \\
\text { of relevant science concepts. Examples: } \\
\text { - Discriminate between appropriate } \\
\text { and less appropriate approaches to } \\
\text { solving problems } \\
\text { - Consider the appropriateness of a } \\
\text { representation for an idea or } \\
\text { compare a representation with the } \\
\text { real thing. }\end{array}$ & 4 \\
\hline 3 & $\begin{array}{l}\text { Student is mostly able to explain/describe all } \\
\text { relevant concepts and utilizes vocabulary, } \\
\text { however, there may be } 1 \text { or } 2 \text { minor } \\
\text { misconceptions and/or inaccurate use of } \\
\text { vocabulary. }\end{array}$ & $\begin{array}{l}\text { Students can frequently give a valid } \\
\text { conclusion based on the correct application } \\
\text { of relevant science concepts. There may be } \\
1 \text { or } 2 \text { minor misconceptions and/or } \\
\text { inaccurate use of vocabulary. }\end{array}$ & 3 \\
\hline 2 & $\begin{array}{l}\text { Student is partially able to explain/describe } \\
\text { relevant concepts, but struggles to use } \\
\text { appropriate vocabulary. Some misconceptions } \\
\text { are revealed. }\end{array}$ & $\begin{array}{l}\text { Students can occasionally give a valid } \\
\text { conclusion based on the correct application } \\
\text { of relevant science concepts. }\end{array}$ & 2 \\
\hline 1 & $\begin{array}{l}\text { Student is unable to explain/describe relevant } \\
\text { concepts. Several misconceptions are revealed. }\end{array}$ & $\begin{array}{l}\text { Students can infrequently give a valid } \\
\text { conclusion based on the correct application } \\
\text { of relevant science concepts. }\end{array}$ & 1 \\
\hline 0 & $\begin{array}{l}\text { Evidence either missing or too insufficient to } \\
\text { score. }\end{array}$ & $\begin{array}{l}\text { Evidence either missing or too insufficient } \\
\text { to score. }\end{array}$ & 0 \\
\hline
\end{tabular}


Appendix D: Modified Application of Conceptual Knowledge Rubrics

\section{Rubric for Conceptual Knowledge Assessment}

Give a score of 1 through 4 for each student, using the guidelines outlined in the rubric. No partial credit for anything outside of these guidelines. Accuracy thresholds are included for use with the guidelines for scoring in the rubric.

b.) Acute Angles: matches angle of stem within 10 degrees of 70 degrees Obtuse Angles: matches angles of stem within 10 degrees of 110 degrees a.) Long Sides: less than $1 / 2$ inch variation from 9 or 8 inches (see list of students) Short Sides: less than $1 / 2$ inch variation from 1.5 inches

$\begin{array}{ll}1 & 2 \\ \text {-No response given } & \text {-Response given is } \\ \text { or } & \text { applicable to the } \\ \text {-Response does not } & \text { question, but is } \\ \text { directly address the } & \text { inaccurate } \\ \text { task prompt } & \text { meaning } \\ \text { or } & \text {-At least one set of } \\ \text {-Insufficient evidence } & \text { sides or angles are } \\ \text { given to score } & \text { incorrect }\end{array}$

3
-Response given is
applicable to the
question
and
-Response is accurate
in both side lengths
and shape angles

4

-Response given is applicable to the question and

-Response is accurate and

-Response shows complex understanding of task by including other information that would be helpful to using this scale drawing beyond what is required by the prompt

\section{Rubric for Application of Conceptual Knowledge Assessment PMSP Criteria:}

Consider the appropriateness of a representation for an idea or compare a representation with the real thing.

1
-No response given
or
-Response does not
address question
or
-Insufficient evidence
given to score

\section{2}

-Response given is applicable to the question, but is inaccurate and/or -Only gives example of similarities or difference but not both
3

-Response shows basic understanding of both similarities and differences, including: -general shape of drawing being similar -general size of drawing being different
4

-Response shows complex understanding of both similarities and differences, including but not limited to: -proportionality of drawing being similar -2-dimensional representation of 3dimensional object being similar or different 
Appendix E: Assessment Task Verbal Instructions

Conceptual Knowledge Assessment Instructions: "The plans you (are going to use/already used) while building the boat were drawn by the person who designed the boat to communicate how to make and put together each part, without ever physically speaking to the person building it. You (will be using/used) these plans by taking measurements and scaling up these measurements to know the dimensions in real life. This can be done because everything in the drawing is exactly the same proportion smaller. This is done mostly to save resources of printing and creating life size drawings, which would also be unwieldy to use.

In front of you is the stem, a part of the boat the holds together the sides at the front. You (will be attaching/attached) the sides by using screws and glue. We want to create another set of plans to show someone one side (indicated side) at one-half the size, or at one-half scale."

Application of Conceptual Knowledge Assessment Instructions: "Imagine someone else sees your drawing and decides they want to use it to build a stem for this boat in the future. What things do you think you did a good job representing in the drawing? What things do you think you did not do a good job doing? What does or does not look like the original piece? Why do you think it would be helpful for someone to have your drawing if they were going to make a stem?" 
Appendix F: Descriptions of Instructional Time Experienced by Students

Lessons on Tools and Building Methods: Instructional time spent working with tools and building methods involved the most direct steps to building the boat. These lessons looked very different at the beginning and the end of the class.

In the first few days, the teachers at the Boat School spent a lot of time scaffolding and building student experience with the various tools. This involved some direct instruction in proper technique, safety, care, and adjustment with the tools. After direct instruction with a tool, students were always given some practice time with scrap wood, to immediately put the ideas into action.

Once students had a chance to practice with all of the tools used, they were assigned to various projects on the boat that involved using those tools. If a particular step necessitated greater care, teachers would help advise a student through that step.

One clear illustration comes from the first day of the program, when the first few large structural pieces of the boat are attached. Student 4 and Student 5 were the first to get the practice time in with the drills, so they were asked to help Teacher 1 to put the first few pieces together. In addition to screws, these pieces have a layer of wood glue, which Student 2 and Student 6 were asked to help spread while everything was being aligned.

Teacher 1 was always present through this step to give guidance, and redirect a student if they were not totally sure what was required of them. This was the first step any of these students had seen with the wood that was being used for the project, so at first even the girls who had practice with the drill were hesitant. With a bit of encouragement, each screw came a little bit easier until the step was finished.

Lessons on Math Concepts Related to Boat Building: Instructional time spent working with math concepts was very intentionally designed to only contain aspects that related to the boat building project. Relevance was kept high and obvious for students to make connections easily. These experiences were carefully crafted, most often by Teacher 2 but also by Teacher 1 and Teacher 3 specifically for this class.

Teacher 2 has been doing a foil boat building challenge for students for the past few classes. In this challenge, students are first given free reign to design whatever boat they think will hold the most weight. After each boat is tested, he guides them through figuring out the volume for each boat, and graphing the results as a way to guide their second design. 
Teacher 1 and Teacher 3 also designed a scale drawing activity, to help practice the idea that drawings or plans do not always exactly represent what you will be doing in real life. Each student was assigned a piece of a photograph to draw at much larger size. The pieces were then part of a team building and motivational lesson to help Girls Inc promote their mission for inspiring girls. 
Appendix G: Teacher 1 Observation Details

Teacher 1 Reflection with Students and Modifying Instruction Observations: Observations of activities related to checking in with students and modifying instruction are exemplified in the following observation example.

On the morning on the first day of the class, the teachers split the students split into three groups, to learn about and practice the tools they would be using throughout the project. This was organized as a set of learning centers, where each teacher would stay at one station teaching the same tools. The groups of students would rotate through a new station every 45 minutes. Teacher 1 was in charge of the station where students would learn to use the hand planes (a tool that removes strips of material to shape or smooth a piece of wood.)

During the planning meeting before this class started, the three teachers had talked about trying a new method for teaching the hand planes to students. Previously, each student was given a hand plane and one piece of wood secured in a vice. Students would practice planing that piece down by removing smooth strips. The teachers had mentioned in the meeting that this is not how the plane is used most often in the boat build. They decided that it is more often used to remove excess material from one piece of wood that has been secured to another, making the junction smooth and even. They planned for this station to reflect that application.

Teacher 1 taught the first group of students the original way, with only one piece of wood, and wasn't really happy with the progress of the first group of students. She asked this first group about their experience at her station during the morning snack break. She first asked about how much they thought they learned, and then explained what the alternative method would have been for practice. Unanimously the students said they could see how the alternative method would be more relevant for what they would be doing later in the week, and encouraged her to try the new way with the second and third groups.

Teacher 1 decided to listen to the first group of students and try the new method. She asked that her second group of students build a practice piece of two overlapping pieces of wood to use at her planing station, since they would be coming from practicing with the drills. This also allowed her to set up practice for planing sharp and rounded angles into the outer piece of wood, another skill used later in the boat build.

This is one example of the strength of this teacher's use of various learning styles, and listening to students about what they say will help them learn. Teacher 1 had incorporated these actions into her approach from the first day, and mentioned during her interview that she consciously thought about how best to tap into each student's strengths. 
The enthusiasm for treating students as individuals with individual needs was picked up by Teacher 2 and Teacher 3 later in the week, with each exhibiting these behaviors more often on the fourth and fifth day than had been observed on the first, second, and third day. A table detailing actions similar to this observation for each teacher is organized temporally below:

Encouraging Different Learning Styles and Following Student Enthusiasm Observations Change Over Time:

$\begin{array}{llllll} & \text { Day } 1 & \text { Day } 2 & \text { Day } 3 & \text { Day } 4 & \text { Day 5 } \\ \text { Teacher } 1 & 5 & 1 & 4 & 5 & 4 \\ \text { Teacher } 2 & 1 & 0 & 0 & 4 & 2 \\ \text { Teacher } 3 & 1 & 0 & 1 & 3 & 2\end{array}$

Teacher 1 Preparation and Reflection Observations: Teacher 1 talked about both helping with preparation and taking time for reflection as two activities that would help her if they took place more often during the initial planning meeting. Particularly, she wanted to make sure she knew what lessons she was responsible for each day so that she could have time to read the manual, look over tools, and prepare pieces before students worked with them.

Teacher 3 agreed that this would be something that would help her as a new teacher at Wind \& Oar, and Teacher 2 offered to help coordinate and give advice to help them prepare. By the end of the meeting, all three teachers had planned Day 1 for the class, both from the student and teacher perspectives.

Teacher 1 and 3 took some time over the lunch break on the first day to review what parts of their plan worked or were completed in the morning, and what needed to change and still wasn't complete that they could do in afternoon. After they created a short list, they consulted with Teacher 2 , and all three teachers set out to get ready for the students to return from lunch.

This pattern continued all five days of the class, with mixed involvement of Teacher 2 and Teacher 3 at different stages. Teacher 1 was always active in starting conversations about what had been going well, and making sure everything was ready for students.

Teacher 1 also often was the one to initiate conversation at the end of the day about how the lessons went. She would also check in about how well the progress on the boat matched the markers the teachers had set for completing the project on time.

On the afternoon of the second day, this reflection focused heavily on a pair of experiences that Teacher 1 and Teacher 3 led for the students. The first was a scale drawing activity, where students took sections of a picture to draw larger 
using graph paper. Each student was assigned one section to draw, and then the entire class worked together to put the sections together without seeing the original.

The second experience was a motivational activity. This featured a TED talk by Laura Dekker (the youngest person to ever solo-navigate around the world by sailboat), talks by both Teacher 1 and Teacher 3 about being a woman in predominantly male field of woodworking and fabrication, and three question and answer sessions with female makers at the maker space where the classes were taking place in. The Laura Dekker talk tied the two experiences together, as the drawing activity was a photo was of Laura and her boat at the end of her journey.

The motivational activity was something that the partner organization for this class, Girls Inc., requested. In both the reflection time, and during the research interviews, both Teacher 1 and Teacher 3 mentioned how surprised they were that most of the students had been involved in creating and building already at their age, and how they hope this activity and their personal influence would encourage these students to feel like they were not limited in their interest or abilities based on their gender.

The drawing activity did not go as smoothly as the teachers had anticipated, and each had a lot of feedback about what they saw the students struggling with, and what could be done differently to address these problems if they used this activity again. These reflections and revisions were also shared with the staff of Wind \& Oar not involved with this class, in case other teachers used the activity in the future. 
Teacher 1 Planning and Debrief Time Interview Responses: Teacher 1 mentioned in several comments how time spent after class analyzing how the experiences went is one of the most influential activities for her instruction. After the students were picked up at the end of each day, all three teachers would meet to discuss their individual work with students, what got completed or still needed work, and what they thought needed to be addressed in the next day.

Teacher 1 mentioned that often she did not realize she was confident leading a lesson or directing student effort in a construction step until she was in the middle of it. By knowing that the teachers would meet at the end of each day, and often during the break in the middle of the day, she could leave a project to come back to with students for later. By talking about the trouble she was having, the learning target of a lesson or the finish quality of a step of the boat would be better addressed.

She specifically mentioned her ability to answer questions about fractions and copying angles were two issues she had during this class. All students in this class had some practice with fractions, but the age differences meant that the oldest students had already experienced Algebra 1, while the youngest had been introduced to fractions for the first time last year. She thought that being able to use age-appropriate language and examples was something she developed through these meetings.

Teacher 1 also mentioned that this time was useful to talk about concerns with materials and tools that needed to be addressed. This included parts that would need to be prepared before students could use them, any touch up work that should be finished by the teachers to stay within the completion timeline, and tools that should be adjusted or replaced so students could use them.

In regards to the final point, she mentioned she wanted to be truthful with the students about their work, and the cause of difficulties they were having. She thought that being able to use the reflection time to address issues with tools that caused problems helped her to reassure students in their efforts. She could be honest with the students that what they were doing was good, but the tool was getting in the way. She felt she could promise that any issue would be resolved before they used the tool again, often the same day. She saw this as a way to keep students growing and learning without getting frustrated about limitations outside of their control.

She also mentioned that the debrief time has not always been consistent when working with Wind \& Oar, and was happy to see the move towards setting aside this time each day. She specifically talked about a previous class that ended several hours later in the day. She felt that this resulted in the teachers, 
including herself, often passing on reflection time after class because they were all tired.

She noted that she felt much more lost during that project, and disconnected from what the students were thinking and feeling about their experience each day. This in turn led to frustration on her part in trying to interact with them on a personal level, and address problems in a timely manner so the project could continue in a productive and positive way.

Teacher 1 Creating Positive Relationships Interview Responses: Teacher 1 talked about several experiences she had as a student or tutor previously that she thinks influenced the way she interacts with her own students.

One such practice she picked up from a coworker at a tutoring center she worked at in Seattle, WA. This coworker was an older woman that Teacher 1 noticed always tried to get on eye-level with her students. This woman was not tall herself, and remembered that teachers she had while growing up made her feel like an equal participant in her learning rather than a receptacle for information by employing this same tactic. To Teacher 1 , getting on the same level physically mirrors getting on the same level emotionally for investment in a students education, removing a sense of authority from the teacher.

Teacher 1 also mentioned several practices she had picked up from a writing instructor she had in college. The first thing she appreciated about this professor was his use of the physical space in the classroom to build a more intimate environment. He would arrange desks in a certain way, or position groups during group work in certain places to elicit a sense of community that she appreciated.

The second practice she borrowed from this instructor was his ability to provide feedback that was positive, but useful to developing her abilities as a writer. She referred to this as his "feedback sandwich," where positive attributes of her writing were mentioned first and last, while things she needed to work on were "sandwiched" in the middle. To her, this was a way to show that he read and appreciated her work as an independent writer, but was invested in helping her grow.

Finally, Teacher 1 learned to allow students enough freedom when problem solving that they ultimately felt responsibility for the solution, but also giving guidance along the way. She mentioned this often was a fine balance between leaving a task so open that a student feels there was no guidance at all, and still having a shared experience in learning.

Teacher 1 did mention that she noticed students were frustrated when they did not get an immediate answer from her. She said her approach towards teaching 
is to allow a little bit of frustration, before students finally engage a problem and make sense of it in their own way. 
Appendix I: Teacher 2 Observation Details

Teacher 2 Direct Instruction and Assisting Students Observations: On the third day of the class, Teacher 2 led a conceptual lesson exploring how the volume and shape of a boat lends certain characteristics (like buoyancy and speed) to a variety of designs.

Before taking part in this lesson on volume, students had participated in an experiment in which they were given time to fold an 8" x 8" into a boat that they thought could hold the highest number of nickels. The volume lesson Teacher 2 led was intended to address the designs the students had seen perform well, before they would be given another chance at creating a boat that would hold more nickels.

During the volume lesson, Teacher 2 gave each student another sheet of tin foil to follow along while calculating the volume of each. He created a table on a large white board to organize student models. The height of the sides on each student model was written next to the internal volume, which each student calculated using the equation height $\mathrm{x}$ width $\mathrm{x}$ length $=$ volume.

He then created a table of simplified theoretical boats, where the height of the sides of models was increased from 0 to 4 , by one-inch increments. Students were assigned one ideal model, and told to calculate the volume of that boat. After the theoretical models were in this table, the group created a graph of side height against volume, where height of sides was plotted along the $y$-axis and volume along the $\mathrm{x}$-axis.

They then compared how many nickels the student-made boats held, to the theoretical boats on the graph. Through a set of guided questions, students one by one came to the conclusion that a greater volume would lead to the greater ability to hold weight in a design.

To be able to come up with a theoretical maximum value for volume, students would also need to understand how changing the height of the sides would affect the length and width of the boat. The older students picked this up more readily, while the teacher would check in with a few of the younger students for understanding before moving on each time.

While all students did eventually come to this conclusion, during this final phase of comparing the volume of a design to its ability to support weight without sinking, direct intervention by Teacher 2 was necessary to ensure the youngest students drew the correct conclusions. The data tables and graphs alone were enough for the older students to figure this out on their own. 
This is one example of this teacher's ability to anticipate what steps come next in a lesson or process to ensure that students are engaged and making progress with a concept. At the beginning of the class, Teacher 2 was very comfortable with shaping a lesson and stepping in if he saw a student that was having trouble. Teacher 1 and Teacher 3 were noticeably less comfortable guiding a lesson, and less confident about when to step in and redirect a student's efforts.

After several days working together on this project, and reflecting at the end of each day, I did notice these actions in Teacher 1 and Teacher 3 occur, although not as frequently as with Teacher 2 . A table detailing actions similar to this observation for each teacher is organized temporally below:

\begin{tabular}{llllll}
\multicolumn{2}{l}{ Anticipating Steps/Trouble in a Task } & & & \\
& Day 1 & Day 2 & Day 3 & Day 4 & Day 5 \\
Teacher 1 & 0 & 0 & 0 & 1 & 1 \\
Teacher 2 & 3 & 1 & 4 & 2 & 0 \\
Teacher 3 & 0 & 0 & 0 & 1 & 3
\end{tabular}

Teacher 2 Leading and Collaborating with Colleagues Observations: An unexpected emergency developed towards the end of the boat build, in which an integral framing piece broke while the bottom was being installed. This has not happened during any Wind \& Oar projects previously, so it came as a surprise to all three teachers. Because Teacher 2 was the most experienced in building this particular boat, he took the lead in designing a solution and directing both Teacher 1 and Teacher 3, who in turn directed the student efforts.

Frustration from a majority of the students in the class was immediately visible. Teacher 2 first took the approach of encouraging the students to see this situation as an opportunity to learn to problem solve and apply the techniques they have learned so far to a new situation.

The boat build is planned with an allotted time for each step that allows it to be completed within the 40 hours of class instruction. With such a major process arising in the second half of the project, Teacher 2's ability to anticipate the steps required to complete a project on time was more readily observable.

Teacher 2 assigned two of the older students in the class to directly work with the tools to design and create reinforcing pieces. He assigned four other students the task of getting the boat back to its original shape, and then securing it while the reinforcing pieces were being created and installed. The last five students were going to spend their time cleaning up the area on the boat where the parts broke. This entailed removing any piece that was not salvageable, and sanding away excess glue and wood that could not otherwise be removed. 
The bulk of the repair work took place on the second half of the fourth day of the class, with the students putting the finishing touches on the reinforcements on the beginning of the fifth day. Teacher 2 supervised the creation of the replacement parts and getting the boat back to its original shape, while Teachers 1 and 3 led students through the clean up and preparation necessary before installing the reinforcements.

During his time working with students on this project, Teacher 2 was very clear about what shape the boat needed to end up before installing the reinforcements, and what kinds of reinforcements would be necessary to ensure the boat kept this shape. Students were given some room to design a solution that they could claim as their own, but he did not allow them to start crafting the pieces until the design they came up with was one he thought would work.

All of the lessons and procedures for Wind \& Oar have at least been discussed between teachers before being implemented in the classroom, while most of these have also been rehearsed by the teachers or practiced with previous classes. The time constraint imposed due to this part breaking near the end of the fourth day, the unrehearsed nature of repairing this part, and the fact that Teacher 2 immediately took the lead in directing efforts to solve this problem, may account for Teacher 1 and Teacher 3 mimicking Teacher 2's this more direct approach with students. 
Appendix J: Teacher 2 Interview Details

Teacher 2 Working from a Student's Starting Points Interview Responses: The Wind \& Oar Boat School often does not have time to do a formal assessment for each student at the beginning of a class, and Teacher 2 mentioned that he is always using his observations of the students as a formative assessment. This ranges from watching them measuring and using tools on the first day, as well as seeing how well each step of the boat turns out along the way.

The most common misconceptions he needs to address with students are in using fractions. The plans used for each boat build are written in Imperial units, and nearly always include a fraction of an inch. Additionally, each set of plans is drawn to a different scale, and that particular ratio needs to be used when determining measurements for the final pieces.

The teachers at Wind \& Oar always use an activity called the "Magic Inch" on the first day of class, to help students get used to the tape measure and familiar with the hash marks used to note different fractions of an inch. In addition to having students practice measuring one piece, Teacher 2 says he uses the time to have students add or subtract fractions as an informal assessment.

He starts by leading the "Magic Inch" activity. This involves each student folding a piece of paper to create a larger version of one inch, with hash marks and reduced fractions included in pencil. He then relates the model they have just created to the real version on a tape measure, which does not always include all of the fractions written numerically.

After students have a chance to look at an inch on a tape measure, Teacher 2 assigns him or her a scrap of wood to individually measure and write down the length. He will then have them mark where they would cut their piece of wood to remove a certain length from the whole. The length to be removed always includes a fraction of an inch with a different denominator than their original measurement.

He mentioned that he most often notices that the spatial awareness in measuring from one place to another is confusing. The example he gave is that if you are watching a student measure something that is two and one-half inches, sometimes they will measure to the two-inch mark, and then measure the next half-inch; or they might measure to the two-inch mark and get confused; or measure to just one-half-inch mark; or measure two individual half-inches; or measure to the two-inch mark and then measure two-sixteenths (the smallest hash mark on the tape measures used at Wind \& Oar).

Watching this simple task allows him to get an idea of each student's history with math education. By knowing the progression of concepts in math 
classrooms, he can tell if they would have trouble with isosceles triangles (used in the shape of the finished boat), since it usually comes after fractions.

Teacher 2 Asking Questions Interview Responses: Teacher 2 completed a Masters of Arts in Teaching at Lewis and Clark University, which included a student teaching experience to complete his licensure. His student teaching experience took place in a $6^{\text {th }}$ and $7^{\text {th }}$ grade classroom in Portland, OR.

He spent some time talking about graduate school and student teaching as a formative experience for his teaching. He mentioned that both his professors at Lewis and Clark, and his cooperating teacher during student teaching, emphasized the use of asking questions rather than giving answers immediately. He thinks this is especially true for math education, and still actively tries to incorporate this into what his students experience while he teaches.

Growing up taking woodworking classes, he experienced this approach from the perspective of a student many times. In particular, he remembers a $6^{\text {th }}$ grade capstone project building a piece of furniture that called for a twisted dovetail. This was something he had never created or worked with before; but the teacher assigned this project because he knew it would challenge him.

Teacher 2 enjoyed these experiences in woodworking, visualizing and figuring out complex geometry, so much that he initially entered college to pursue mechanical engineering. He sees this as a testament to the influence a teacher can have through appropriately challenging his or her students.

Teacher 2 sees asking questions to students as important in that it serves as a model for them to emulate. They can see what information they need to gather to answer a particular question they have, and then refine their question if there is not enough background information available. Teacher 2 also mentioned that it helps students focus less on procedural understanding or memorization of facts, and more on the ability to form questions and connections related to finding an answer on their own.

On the opposite end of the spectrum, Teacher 2 believes that talking too much before students start doing something can be detrimental. Finding the balance of being thorough about why students are going to complete a task, but not talking so much they check out before starting, is something he worked on throughout student teaching.

He said that the most frustrating thing he has experienced as a teacher is a student who just accepts that they don't know something, and are resigned to not knowing. He mentioned that it is hard to work with a student who has no interest in learning or knowing something they don't already know. 
His time with the class followed in this research project was particularly pleasant for him, because he did not observe a disinterest in learning in any student. He mentioned that this made it easier to assess where the students were academically, and to help move them forward in their understanding of math.

When planning for future development, Teacher 2 noted that he would like to improve his questioning technique to lead students to a better understanding of what they are doing. If done right, he thinks it can lead students to an ability to see problems for themselves, or figure out the next steps to solving a problem when they get stuck. 
Appendix K: Teacher 3 Observation Details

Teacher 3 Anticipating Student Difficulties by Giving Detailed Instruction Observations: On the second day of class, Teacher 3 led a scale drawing activity with Teacher 1 for half of the students, while the other half worked with Teacher 2 on the boat directly. This activity took about 45 minutes, and once completed the two groups switched, so that everyone would get equal time with the boat and math enrichment activities.

Teacher 3's activity centered on a photograph of Laura Dekker, a woman who became the youngest person to solo-navigate the Earth by sailboat. This photograph was split into a grid of 12 equally sized squares, and the students were drawing their allotted section four times larger than the original.

After both groups had completed their section, they were told that they would be responsible for arranging each section into a complete photo, without having seen the original. Laura Dekker would be the focus of a presentation and discussion later in the day about perseverance and following your dreams as a young woman.

As a member of the fabrication team for the maker's space where this class was taking place, Teacher 3 regularly builds objects from wood and metal using scale plans. Later in her interview, Teacher 3 mentioned that while teaching the first group of students, she realized she really didn't have a good idea of how to explain the idea of scale to someone else despite this regular practical use.

During the morning snack break and between the first and second groups of students, she talked with Teacher 1 and Teacher 2 about the trouble she was having. Teacher 3 mentioned Teacher 1 and Teacher 2 helped by giving advice about how they would approach the activity if they were leading it.

While observing Teacher 3 facilitate the experience with the second group of students, I noticed that she avoided giving a long introduction to what they were doing, and rather used a combination of modeling and age-appropriate conceptual examples (the former at the suggestion of Teacher 1, the latter at the suggestion of Teacher 2) to help explain the task and the purpose. The time it took for students to become engaged and start on the task was significantly shorter, and the end products contained more attention to detail than with the first group.

In this way she was able to incorporate the advice of her co-teachers, while trying to anticipate problems students were going to have before the task began. Later she mentioned how frustrated she felt while working with the first group of students. She said thought this frustration came from feeling surprised and embarrassed that she did not understand something she uses every day as well 
as she thought she did. She also mentioned being grateful for the help she was able to quickly get from the other teachers, and that by incorporating their suggestions was able to come to a better conceptual understanding herself.

I noticed at the start of the week that Teacher 3 most often employed her strategy of anticipating difficulties when working on something she thought would be entirely new to students. Her approach consisted of trying to give all possible knowledge on a concept or procedure, using unambiguous language. This often manifested as a complete explanation for each facet of a concept, or step-by-step directions for processes.

She also mentioned in her interview that she wanted to seem very prepared for students before the class started, and spent a lot of time trying to learn every detail of what she would be teaching that day. She said she thought that if the students thought she knew what she was talking about, then they would be more likely to listen to her.

Throughout this week, Teacher 1 was much more concise, while Teacher 2 employed a similar strategy at times. I noticed that the more time Teacher 1 and Teacher 3 spent working together, the less common it was for Teacher 3 to anticipate student difficulties using only verbal instruction.

Throughout this week, the teachers all worked with students individually at some times, and in groups at other times. Most of the group-times saw Teacher 1 and Teacher 3 paired together, while Teacher 2 worked with students alone. This may have led to Teacher 3 adopting a multi-model approach to anticipating student problems, similar to Teacher 1 . A table detailing actions similar to this observation for each teacher is organized temporally below:

Giving Detailed Instructions

$\begin{array}{llllll} & \text { Day } 1 & \text { Day } 2 & \text { Day } 3 & \text { Day } 4 & \text { Day 5 } \\ \text { Teacher } 1 & 1 & 0 & 1 & 1 & 1 \\ \text { Teacher } 2 & 0 & 2 & 3 & 0 & 2 \\ \text { Teacher } 3 & 4 & 0 & 3 & 0 & 1\end{array}$

Teacher 3 Learning New Tools and Procedures Observations: Most of Teacher 3's training in woodworking and metalworking has been with the use of power tools. Much of the Wind \& Oar program requires the use of hand tools, both as a safety measure and as a way to help students focus thoughtfully on each step.

Because this was the first class Teacher 3 helped to teach with Wind \& Oar, Teacher 2 scheduled a planning meeting the week before the class started. All three teachers attended to plan and ask any questions they might have. 
Teacher 3 was given a set of the plans, and Teacher 1 and Teacher 2 helped to walk through the first few days' activities with her. Teacher 1 and Teacher 3 also spent time looking at the tools Teacher 3 was unfamiliar with that she would need on the first day. These tools included the hand plane and bevel gauge (a tool used to transfer angles from one piece of wood to another).

The students in the class were split up into three groups on the first day, to rotate through several stations learning several of the tools. Teacher 3 was assigned to teach students to use the handsaw, a tool she has used sparingly in her work previously. For the first group, she initially fell into her method of describing the procedure in detail verbally, before allowing students to practice cutting scrap wood.

Several students in the first group experienced some trouble with the saw binding. The saws being used cut on the pull stroke only, while most students seemed to be experienced with saws that cut while both pulling and pushing. The students were using equal force in both directions, which often causes the saw to bind in their piece of wood.

Teacher 3 did explain this detail when first teaching her students how to use the saw. When students started having trouble with the saws binding, she tried explaining the principles again in the same way, which some students picked up on while others did not. Teacher 3 was very confident in describing the proper procedure when introducing an activity, but was noticeably less confident about when to step in when students were experiencing difficulty or confusion in practicing.

She mentioned later in her interview that with the first group of students practicing sawing, if a student had trouble getting a clean or fast cut she didn't really know what to say besides "keep trying." The first group of students came to her station, before a small snack break, while the second and third groups of students came after this break.

During the break, she asked Teacher 1 to work with her again. Because this is a tool she has had at least some experience using, it was not one they had reviewed at the planning meeting. Teacher 3 was not sure how to address the specific issues students were having because of this omission. Teacher 1 gave Teacher 3 a few pointers, and she said she approached the next two groups with more confidence.

When students in the second and third training groups experienced saws binding in the wood, Teacher 3 employed a modeling style that Teacher 1 had used during the break. This consisted of a two-part process. The first step was showing each student, up close, what the teeth of the saw looked like, and asking him or her to describe the shape and try to explain why that shape might have 
been important. The second step was to demonstrate the pressure necessary in the saw stroke in each direction, followed by helping each student set up their body and take the first few strokes with ideal position and pressure.

When some students still had trouble with the saw binding, she asked them to model what they thought was happening based on the design of the tool they were using and how they were using it. Students came back to the shape of the teeth and the angle of the saw, and this second time were able to make the connection by deciphering the design of the tool. 
Appendix L: Teacher 3 Interview Details

Teacher 3 Reviewing and Practicing Interview Responses: Teacher 3 talked about the drawing experience using the Laura Dekker photograph as one time she needed to review a concept and how to teach it.

She said she was surprised at first, because she thought she understood ratios well. She uses them every day while fabricating in her job at the maker's space. When she had to verbalize what a ratio is and how you can use them, she felt that she just didn't know how to put her understanding into words.

Teacher 3 said she wanted to talk with one of the Wind \& Oar teachers during the break, because she recognized that she needed more practice presenting ratios before she worked with her next group of students.

By working with Teacher 1 , she was able to learn a new approach to teaching ratios. In the next groups she was able to present the idea a few different ways to help students with different understanding to move forward.

She also mentioned being a little bit daunted by teaching students to use tools that she did not have a lot of experience working with. While the tools were not entirely new to her, most of the projects for her job were completed using power tools.

Teacher 3 said that after the initial planning meeting, she was able to work with Teacher 1 to learn more about the hand tools the students would be using. Teacher 3 was also able to help Teacher 1 and Teacher 2 to prepare some of the larger pieces of wood in the days before this class started.

She said her approach was to first ask for help from her co-teachers, but if they were not around she was not content to not know. She thinks the Internet has changed how people learn dramatically. She believes you can learn about anything you want by using your computer.

Teacher 3 used this resource several times throughout the course of the class. Specifically, she noted that this was helpful in planning the motivational talk featuring Laura Dekker, as well as reviewing the hand plane.

Teacher 3 Answering Specific Student Questions Interview Responses: Teacher 3 also talked about her desire to appear to be a knowledgeable and capable teacher to the students. She said she thought this would be beneficial in a couple of ways.

The first benefit she thought this approach would have is to foster trust for her in the students. Teacher 3 thought that if the students believe that she knew 
what she was talking about, they would have faith in her to be able to help them when they needed it.

The second benefit she thought that this approach would have was to motivate the class to realize females can do anything they want to do. This aligned with one of the goals that Girls Inc. had for this class as well, and Teacher 3 thought that it was an important idea to address.

She thought that she could be a positive role model for her students, if they could see how competent she was both with the tools and with the math. Teacher 3 also mentioned that if she found out later on that someone in her class was motivated to pursue a career they didn't think they could do before Wind \& Oar, then she would consider her job successful. 
Appendix M: PH Stat Raw Data Analysis

Conceptual Knowledge Task Analysis Output

\begin{tabular}{|c|c|}
\hline Data & \\
\hline $\begin{array}{l}\text { Level of } \\
\text { Significance }\end{array}$ & 0.05 \\
\hline $\begin{array}{l}\text { Population } 1 \\
\text { Sample }\end{array}$ & \\
\hline Sample Size & 7 \\
\hline Sum of Ranks & 49 \\
\hline $\begin{array}{c}\text { Population } 2 \\
\text { Sample }\end{array}$ & \\
\hline Sample Size & 7 \\
\hline Sum of Ranks & 56 \\
\hline \multicolumn{2}{|c|}{ Intermediate Calculations } \\
\hline $\begin{array}{l}\text { Total Sample } \\
\text { Size } \mathrm{n}\end{array}$ & 14 \\
\hline T1 Test Statistic & 49 \\
\hline T1 Mean & 52.5 \\
\hline $\begin{array}{l}\text { Standard Error } \\
\text { of } T 1\end{array}$ & 7.8262 \\
\hline$Z$ Test Statistic & -0.447214 \\
\hline Lower-Tail Test & \\
\hline $\begin{array}{l}\text { Lower Critical } \\
\text { Value }\end{array}$ & -1.6449 \\
\hline p-Value & 0.3274 \\
\hline \multicolumn{2}{|c|}{$\begin{array}{c}\text { Do not reject the null } \\
\text { hypothesis }\end{array}$} \\
\hline
\end{tabular}

Application of Conceptual Knowledge Task Analysis Output

\begin{tabular}{|c|c|}
\hline Data & \\
\hline $\begin{array}{l}\text { Level of } \\
\text { Significance }\end{array}$ & 0.05 \\
\hline $\begin{array}{l}\text { Population } 1 \\
\text { Sample }\end{array}$ & \\
\hline Sample Size & 7 \\
\hline Sum of Ranks & 43.5 \\
\hline $\begin{array}{l}\text { Population } 2 \\
\text { Sample }\end{array}$ & \\
\hline Sample Size & 7 \\
\hline Sum of Ranks & 61.5 \\
\hline Intermediate & Iculations \\
\hline $\begin{array}{l}\text { Total Sample } \\
\text { Size } n\end{array}$ & 14 \\
\hline T1 Test Statistic & 43.5 \\
\hline T1 Mean & 52.5 \\
\hline $\begin{array}{l}\text { Standard Error } \\
\text { of } T 1\end{array}$ & 7.8262 \\
\hline Z Test Statistic & -1.149978 \\
\hline Lower-Tail Test & \\
\hline $\begin{array}{l}\text { Lower Critical } \\
\text { Value }\end{array}$ & -1.6449 \\
\hline$p$-Value & 0.1251 \\
\hline \multicolumn{2}{|c|}{$\begin{array}{c}\text { Do not reject the null } \\
\text { hypothesis }\end{array}$} \\
\hline
\end{tabular}




\title{
Appendix N: Approved IRB Application
}

\section{f Portland $\underset{\text { UNIVERSITY }}{\text { State }}$}

\author{
Post Office Box $751 \quad 503-725-2227$ tel \\ Portland, Oregon 97207-0751 503-725-8170 fax \\ Human Subjects Research Review Committee \\ hsrrc@lists.pdx.edu
}

Date: Melissa Potter / Christopher Wood

To:

From: Karen Cellarius, HSRRC Chair

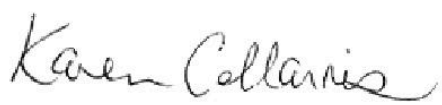

Re: $\quad$ HSRRC approval for your project titled, "How Does a Teacher's Experiences and Training Affect Their Pedagogical Content Knowledge in Math And How Does the Experience of the Wind \& Oar Boat School Affect Students' Abilities To Do A Scale Drawing?"

HSRRC Proposal \# 153402

Approval-Expiration: June 8, 2015 - June 7, 2016

Review Type: $\quad$ Expedited, Category 7

In accordance with your request, the PSU Human Subjects Research Review Committee has reviewed your request for approval of the project referenced above for compliance with PSU and DHHS policies and regulations covering the protection of human subjects. The Committee is satisfied that your provisions for protecting the rights and welfare of all subjects participating in the research are adequate, and your project is approved. Please note the following requirements:

Approval: You are approved to conduct this research study only during the period of approval cited above; and the research must be conducted according to the plans and protocol submitted (approved copy enclosed).

Consent: Signed consent is required from all participants in this study.

Changes to Protocol: Any changes in the proposed study, whether to procedures, survey instruments, consent forms or cover letters, must be outlined and submitted to the Committee immediately. The proposed changes cannot be implemented before they have been reviewed and approved by the Committee.

Continuing Review: This approval will expire on 06/07/2016. It is the investigator's responsibility to ensure that a Continuing Review Report on the status of the project is submitted to the HSRRC two months before the expiration date, and that approval of the study is kept current. The IRB offices does not send out notifications of expiration dates. The Continuing Review Report is available at www.rsp.pdx.edu/compliance_human.php and in the Office of Research and Strategic Partnerships (RSP).

Adverse Reactions and/or Unanticipated Problems: If any adverse reactions or unanticipated problems occur as a result of this study, you are required to notify the Committee immediately. If the issue is serious, approval may be withdrawn pending an investigation by the Committee.

Completion of Study: Please notify the Committee as soon as your research has been completed. Study records, including protocols and signed consent forms for each participant, must be kept by the investigator in a secure location for three years following completion of the study (or per any requirements specified by the project's funding agency).

If you have questions or concerns, please contact the Office of Research Integrity in the PSU RSP at 503-725-2227. 